Journal of Jazz Studies vol. 9, no. 1, pp. 53-93 (Summer 2013)

\title{
Dave Brubeck's Definitive "Jazzanians"
}

\author{
Vasil Cvetkov
}

On December 5, 2012, American contemporary music lost one of its most important personalities-pianist and composer Dave Brubeck, who died one day before his 92nd birthday. His death marks the passing of one of the most creative and versatile musicians in American history. Widely known as an innovative jazz musician, Brubeck's skills in writing and arranging music for classical ensembles went far beyond jazz traditions, making him a subject of interest and investigation for contemporary music researchers. He became an emblematic figure for those, who, like me, received a classical music upbringing and became fascinated by his ability to fuse jazz and classical sources into the specific style that eventually became his trademark.

Despite having received a classical education, I have always been attracted by the jazz sound, so that discovering and demonstrating the plenitude of Brubeck's legacy became a natural research goal in my graduate studies. In planning this personal tribute to the late Dave Brubeck, I came to the conclusion that, perhaps, the most eloquent examples of his unique compositional style could be demonstrated around the story of a little tetrachord. Throughout a period of 17 years (1987-2003), it inspired Brubeck to create five important compositions and came to be known, by those who love Brubeck's music, as the "Jazzanians tetrachord." The compositions varied in form, covering the full spectrum of jazz, classical, and fusion styles. I call these compositions "realizations."

Trying to trace Brubeck's realizations chronologically through that 17year period, I first examined published scores but discovered that there were mysterious gaps. I found Internet performances and obtained recordings that were not related to any of the published scores. For example, watching a DVD of Brubeck's second tour in Russia, I heard a short excerpt of orchestral background music which included the "Jazzanians" theme. I realized this was yet another version of the "Chorale" that I had studied as a published score. ${ }^{1}$ Russell Gloyd, Brubeck's artistic manager, sent me the full recording of that

${ }^{1}$ The second movement of Chromatic Fantasy Sonata.

copyright by author $\left(\right.$ C) $\begin{array}{l}\text { Except where otherwise noted, this work is licensed under } \\ \text { http://creativecommons.org/licenses/by-nc-nd/3.0 }\end{array}$ 
performance, but there had never been a published score. Some concerts by Brubeck contained new material but were recorded privately and never released to the public or published as scores. The only way to analyze and compare recordings and published scores was to transcribe the recordings.

John Salmon, editor of the book Seriously Brubeck, kindly offered his private correspondence with Brubeck and advised me to request manuscripts from the Brubeck Collection in the Holt-Atherton Special Collections at the University of the Pacific Library. To my surprise, I was able to request a huge box of copies from the Collection. In the box were hundreds of photocopies of scores with Brubeck's handwritten notes and different versions of compositions that include the "Jazzanians" tune. Making sense of the masses of wonderful material was a challenge because the chronology was not clear. The only way to map the development was to compare printed programs of concerts with the various recordings, scores, and manuscripts.

My quest led, ultimately, to Brubeck himself and later to his son Darius. Imagine the thrill of seeing Dave Brubeck after a concert, waiting for me in the lobby of his hotel in New York City. Using all these sources, I set out to trace the history of the "Jazzanians" theme and to analyze five different recorded performances, or realizations, of the theme as a single tune and as part of extended versions. A main challenge of this study was transferring the data from the different styles and putting them in order. This article traces chronologically how Brubeck used the "Jazzanians tetrachord" from the development of his original idea to the final version in large-scale works from his late period, such as The Chromatic Fantasy Sonata. Above all, this study of the various incarnations of the "Jazzanians" will try to demonstrate how Brubeck's rich imagination allowed him to develop the same motive in various ways so as to achieve completely different results, while the motive itself, throughout such a long period of time, remained for Brubeck a fresh source of inspiration.

My analysis of these instrumentally and stylistically different performances will provide new information about their musicological context. It will demonstrate the importance of the "Jazzanians" tune in the creation process of all five realizations and discuss the various types of development the tune underwent during the whole timeline. My analysis will also reveal the compositional techniques explored within each realization. The analytical methods will involve comparative studies of the performances in terms of form, structural development, orchestration and arrangement. The investigation of the manuscripts helped to reconstruct the compositional process from inspiration to realization. 
Another challenge was to reconstruct the process of adapting the material for a chosen ensemble and venue, for which the obtained manuscripts and scores were of significant help. The main reconstruction tools were tracing, comparison and analysis of the main "Jazzanians" motive and the process of structural development of all performances.

While exploring his compositional techniques, I kept wondering why he repeatedly used those same four notes and why they sparked so much creativity. What was he searching for? Each composition, or "realization," appeared to be definitive, but then, sometimes years later, he had a new idea and developed another "definitive" realization.

\section{OVERVIEW}

In order to trace the origin of the name Jazzanians we need to go back to the year 1983 when Dave Brubeck's son Darius became the founder of the first African jazz degree program at the University of KwaZulu-Natal, formerly the University of Natal (UND), South Africa. In a letter to me, Darius explained that his family's connections with South Africa had been established long time before that: "'The New Brubeck Quartet' (Dave, Chris, Dan and I) toured SA in 1976, of all years, albeit before the declaration of the UN cultural boycott."

At a conference in Amsterdam called "Rhythm Changes: Jazz and National Identities Conference" (2011) Darius Brubeck recalled: "In 1983, I accepted a two-year 'music theory' post at the University of Natal, but the real agenda was to set up a degree in jazz, the first in Africa." ${ }^{3}$ The first great international success of this jazz program came five years later at a conference in Detroit, at which it was represented, among others, by a student jazz band called Jazzanians. In his presentation in Amsterdam, Darius Brubeck described the evolution of its success:

With the great student talent we had in 1987, we felt we could go international. Cathy Brubeck initiated, raised funds and organized the first multi-racial student jazz band from South Africa to participate in the National Association of Jazz Educators (later IAJE) Conference, which was held in Detroit in 1988. This was 4 years on from police breaking up racially mixed performances on campus and now, thanks to the late, famous jazz pianist and TV host, Billy Taylor, our student band 'The Jazzanians'

\footnotetext{
${ }^{2}$ Darius Brubeck, quoting from his publication in the South African Mail and Guardian, December, $22^{\text {nd }}, 2012$.

${ }^{3}$ Darius Brubeck, speaking at the Rhythm Changes: Jazz and National Identities conference in Amsterdam (2011).
} 
appeared on NBC and CBS-two major TV networks in the U.S. ${ }^{4}$ It was an emotional and politically charged journey, but ultimately a successful one. ${ }^{5}$

The appearance at the 1988 conference marked the student band's tour of the United States. The members of the band were from "multiple cultures of South Africa-Zulu, Xhosa, English, Dutch-and they played a passionate music that stemmed from African roots with an overlay of Western Jazz and popular township music." ${ }^{6}$ When the Jazzanians appeared at the International Association of Jazz Educators [IAJE] conference, it did so with the approval of the Black Caucus of the U.S. Congress. ${ }^{7}$ The IAJE itself organized donations of instruments and books, Jamey Aebersold donated his entire Play-along series, and Dave and Iola Brubeck hosted the touring band members in their Connecticut home. It was in midst of these inspiring events that the "Jazzanians" tune appeared.

The idea of this tune came from a very pleasant occasion: Shortly after Christmas, 1987, Darius brought nine of his students [from Africa] to the United States to the International Association of Jazz Educators gathering in Detroit. Iola [Brubeck's wife] and Dave had all of them, plus the other brothers, their sister, and assorted grandchildren in the Wilton house over the holidays. The talk, the noise, the food, and, above all, the music that went on constantly inspired Dave to compose a piece called "Jazzanians"

Dave Brubeck's liner notes in At The Piano with Dave Brubeck (1993) explained that the name of the tune was a tribute to this student jazz band. A short draft of the tune (not dated), with the title "Jazanians" (missing a " $z$ ") written in Brubeck's hand is preserved among his papers in the Brubeck

\footnotetext{
${ }^{4}$ A presentation of Jazzanians is available on YouTube at: http://www.youtube.com/watch?v=8V6B8XvxX_c

${ }^{5}$ Darius Brubeck, speaking at the Rhythm Changes: Jazz and National Identities conference in Amsterdam (2011).

6 Tom Roed, ed., At the Piano with Dave Brubeck. Intermediate Solos Arranged by Dave Brubeck (Miami, FL: CPP/Blewin, Inc, 1993), 5.

According to Darius Brubeck, the original members of the Jazzanians band were: Johnny Mekoa, Zim Ngqawana, Nic Paton, Rick Van Heerden, Andrew Eagle, Melvin Peters, Victor Masondo, Kevin Gibson and Lulu Gontsana. Dave and Iola Brubeck hosted four more South African student bands and helped them with logistics, donations and friendship throughout the years.

${ }^{7}$ Updated information about the band is available at: http://www.3rdearmusic.com/reissue/jazzanians.html

${ }^{8}$ Fred M. Hall, It's About Time: The Dave Brubeck Story, (Fayetteville, AR: University of Arkansas Press, 1996), 100.
} 
archive at the University of the Pacific in California. This draft includes the first sixteen bars of the original composition and even has the text "JAZAN-I-ANS" placed under the main melodic phrase (mm. 1-4) in the right hand.

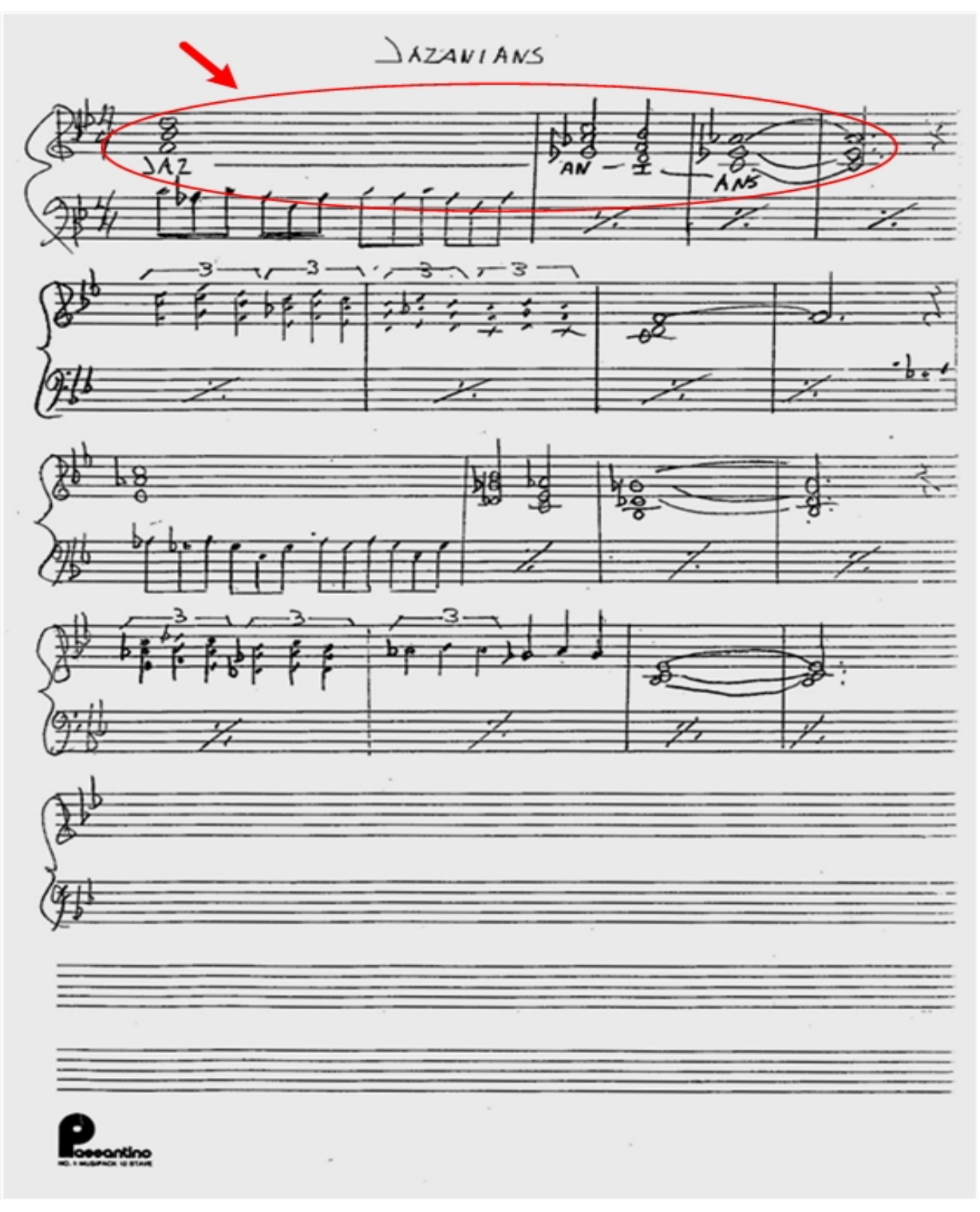

Example 1a. Manuscript of Dave Brubeck, "Jazzanians."19

9 [“Jazzanians," manuscript, Box 3A.14.22: "Jazzanians"] Brubeck Collection, Holt-Atherton Special Collections, University of the Pacific Library. (C) Dave Brubeck 
The analysis of the draft shows that the melody is represented by the whole tone "Jazzanians" motive, $\mathrm{D}-\mathrm{C}-\mathrm{B} \mathrm{b}-\mathrm{A} b$ (repeated with upper neighbor motion and then transposed). This whole-tone tetrachord is stated in long-note values over an unchanging ostinato bass.

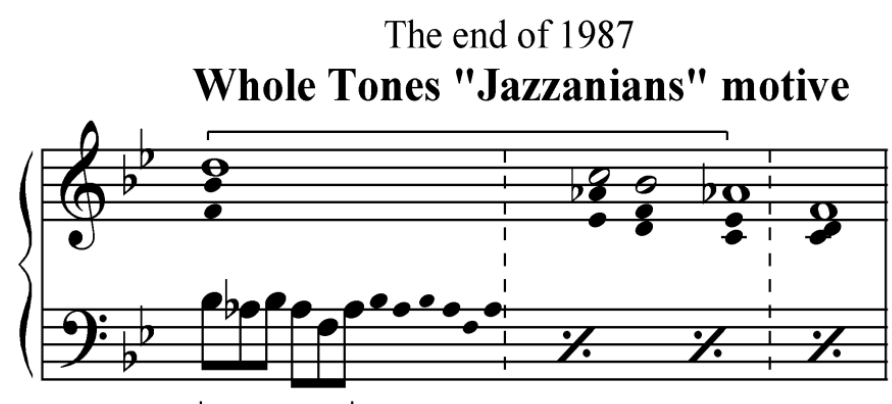

Ostinato motive

Example 1b. The main motive.

Later, in the summer of 1988 , in a sketch for a different composition called "Unscholarly Fugue for String Quartet or String Orchestra," Brubeck created two 12-tone themes representing a subject (mm. 1-4) and a countersubject (mm. 5-8). 


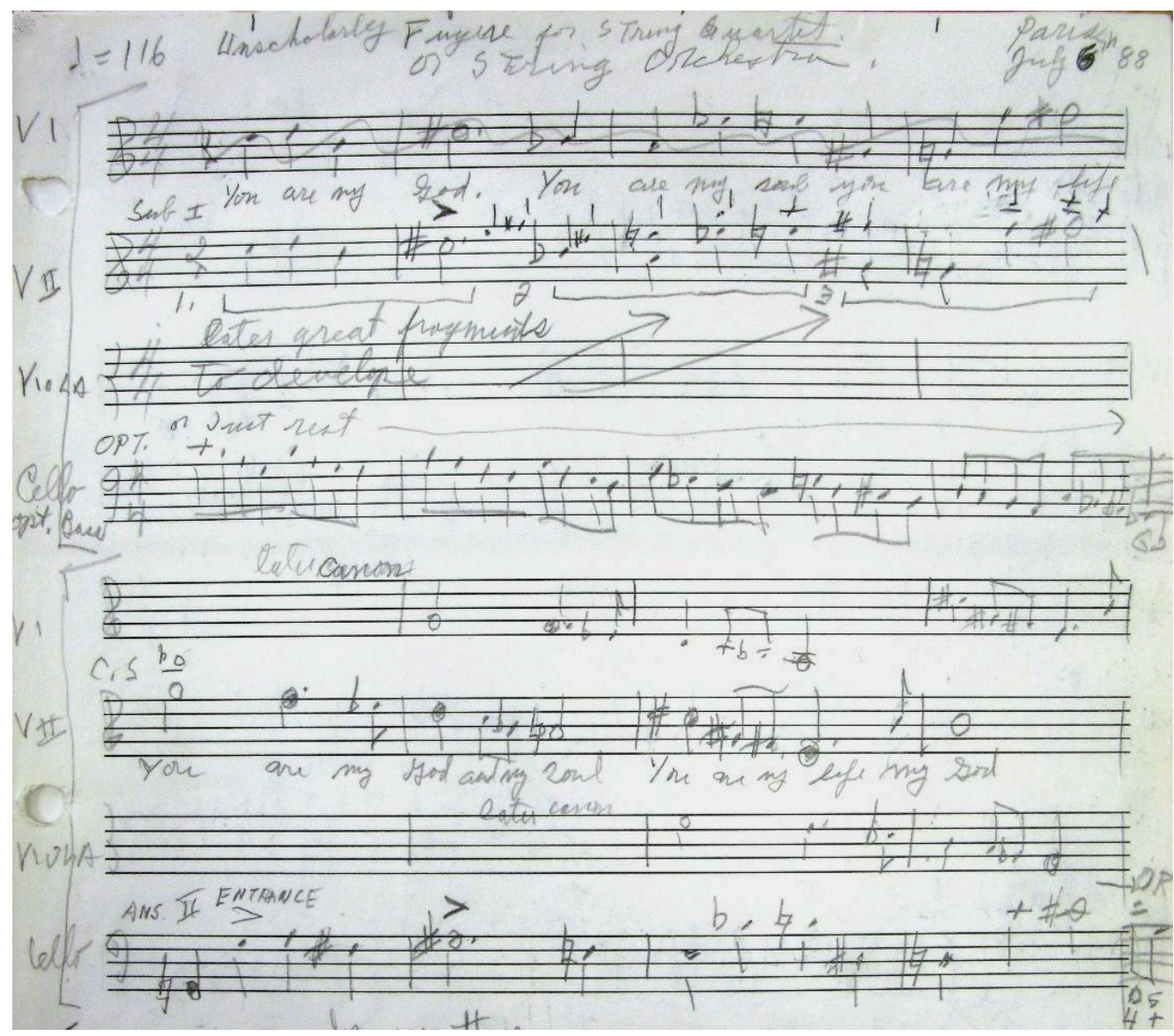

Example 2. Manuscript of Dave Brubeck, sketches for "Unscholarly Fugue."10

In the countersubject (the 12-tone theme), the descending tetrachord at the beginning is not a whole-tone tetrachord, but rather a diatonic variant commonly known as the "Lament" tetrachord [G-F-Eb-D]. ${ }^{11}$ This centered Lament tetrachord represents an altered version of the "Jazzanians" whole-tone motive. Brubeck repeats this tetrachord twice, creating a diatonic heptachord $[\mathrm{G}-\mathrm{F}-\mathrm{E} b-\mathrm{D}-\mathrm{C}-\mathrm{B} b-\mathrm{A}]$, and finalizes the theme with a diatonic pentachord [C\#-B-G\#-F\#-E].

${ }^{10}$ ["Unscholarly Fugue," manuscript] Brubeck Collection, Holt-Atherton Special Collections, University of the Pacific Library. (C) Dave Brubeck

${ }^{11}$ Music theorists call this tettrachord the "Lament" because it is in a minor mode and similar in structure to seventeenth-century laments. (See for example Steven G. Laitz The Complete Musician, p.273-275.) 


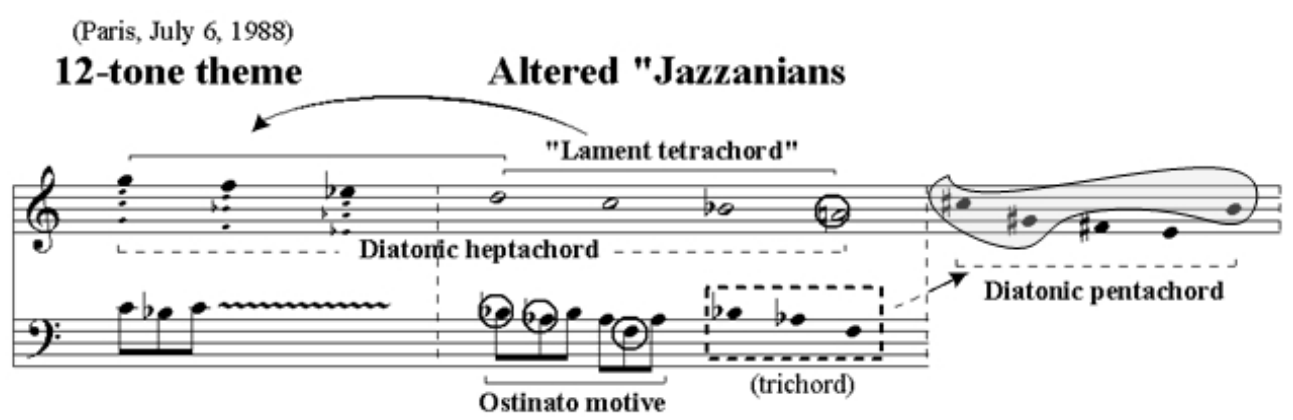

Example 3. The 12-tone countersubject scheme of the motives.

The Lament tetrachord derived from the "Jazzanians" tune, as well as the entire 12-tone theme found in this 1988 draft was extensively used by Brubeck along with the main "Jazzanians" motive in three of the five realizations discussed in this article: namely, The Quintet Sonata, Chromatic Fantasy for String Quartet and Chromatic Fantasy Sonata, as well as in a piano solo, unrecorded version, published in 1993.

Both the 1987 and 1988 drafts, which precede all the recorded and published versions, represent the origins of the material that was later developed to create a variety of compositions. Luckily, the preserved documents, besides allowing us to establish with precision the chronological order of the events, demonstrate the composer's original disposition to develop the material in both jazz and classical directions.

\section{FIRST REALIZATION, THE 1992 RECORDING}

In 1992, Brubeck recorded the tune for the first time with his sons: Chris on electric bass and Dan on drums. ${ }^{12}$ The following comparative analysis will start with this first studio-recorded version. The recording length is 7 minutes and 57 seconds. In this version of the tune (Music Masters, 1993), Brubeck used a repeated 24-measure theme, which is followed by a long improvisational section for piano and drums. A partial transcription is shown in Example 4.

12 Trio Brubeck, Music Masters, 65102-2 (1993). 

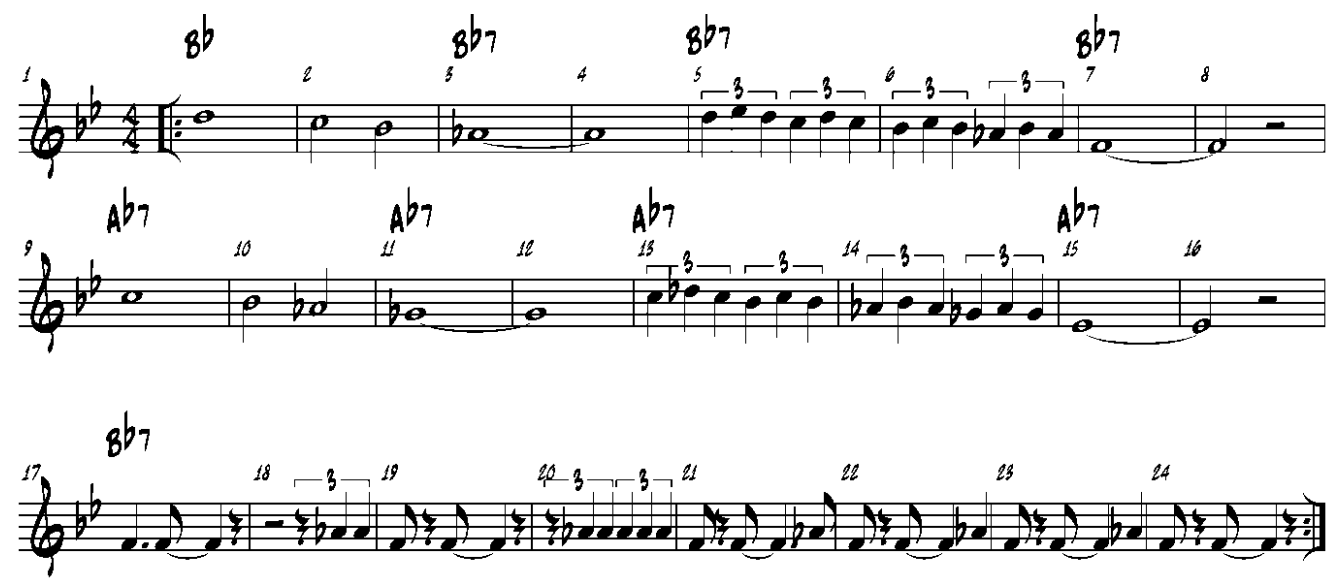

Example 4. Transcription of the 24-measure head theme of "Jazzanians," (from the 1992 recording).

Dave Brubeck's arrangement begins with a sixteen-measure drum introduction. In the last four measures, the electric bass joins the drums, "stating" the main ostinato motive of the theme (see Example 5a). However, from measure seventeen, Chris Brubeck transforms the motive into a twomeasure bass groove line, which is kept throughout the piece. Example 5b presents this bass pattern, which fits the left-hand ostinato motive of the main theme.

Electric Bass

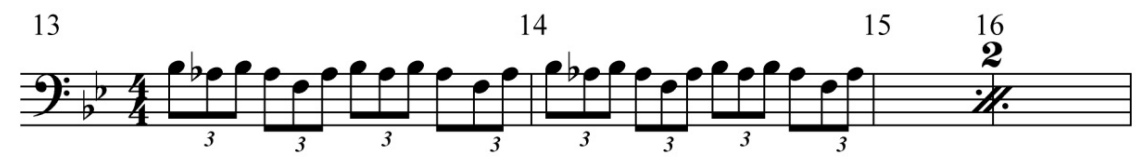

Example 5a. Ostinato motive, mm. 13-16 of the Intro, and the accompaniment of the head.

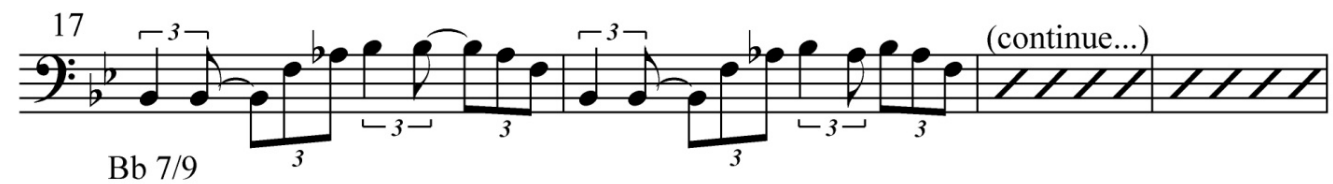

Example 5b. The bass groove line of the entire piece.

The exposition, or "the head," which contains forty-eight measures (twenty-four measures with repetition) is followed by seven and a half choruses of piano improvisation. Throughout the entire performance, with the exception of the drum solo, the piano is in dialogue with the drums as part of the "triangle" relation (typical for a contemporary jazz trio), where the bass line represents the foundation for both improvisers. Dave Brubeck improvises seven 
choruses based on the first sixteen measures of the head and finishes his solo in the first eight measures of the eighth chorus, with five repetitions of $\mathrm{B} b-6 / 9$ chords, which sound like an echo after the culmination in the last chorus. He gradually builds the culmination, dramatically changing the texture from chorus five to chorus seven. All seven and a half choruses of this performance keep the sixteen-measure structure. The recapitulation is also sixteen measures long and represents a shorter version of the head built on the texture of the basic theme, which finishes with a coda, where the piano part fades, yielding to the drum solo. There is no evidence of why the improvisation is exactly seven and a half choruses long. My feeling is that its length may have been determined by a spontaneous decision based on the ongoing unfolding of the culmination.

The piano improvisation in Brubeck's performance can be divided into two parts. The first part, comprising the first three choruses, is a melodic solo improvisation in the right hand with accompaniment (See Example 6a).
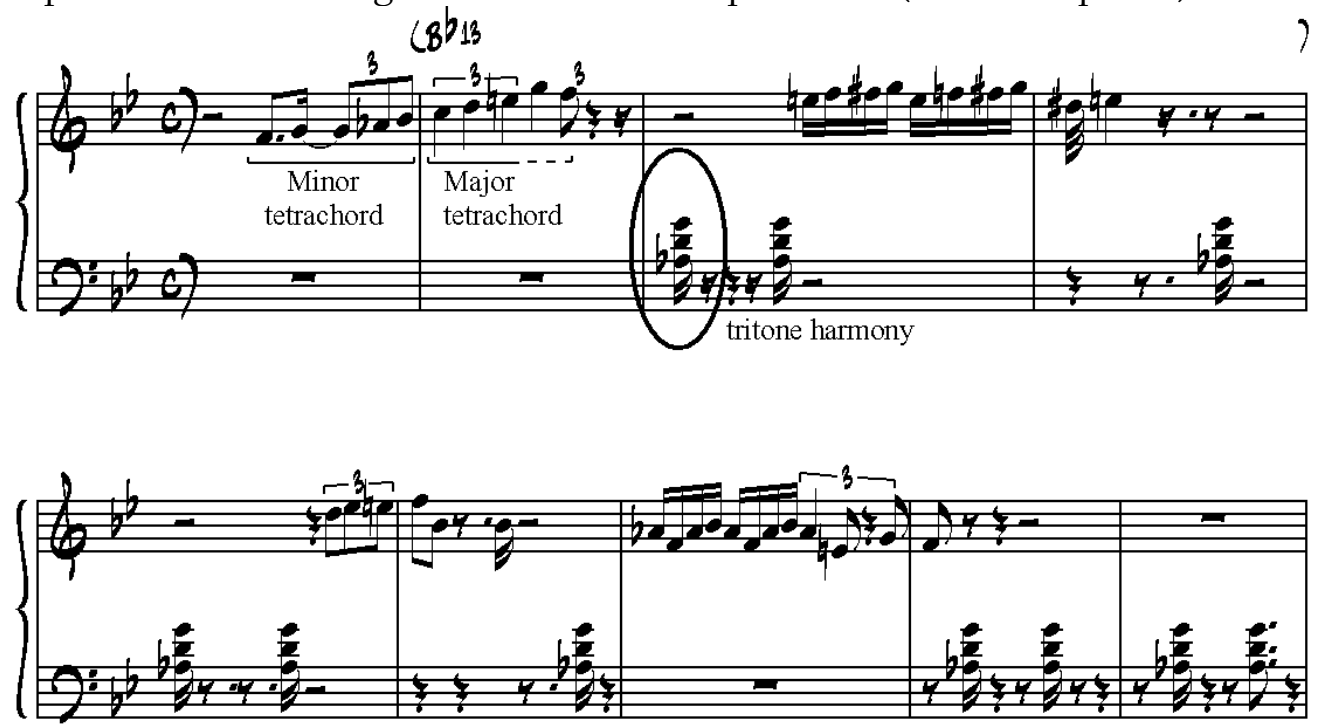

Example 6a. "Jazzanians," First Chorus, transcribed by Vasil Cvetkov.

In the first forty-eight measures, the texture of the improvisation consists of a melodic voice with many motivic repetitions in the right hand over an accompaniment of three-voice chords in the left-hand. In the album's liner notes, Chris Brubeck describes this improvisation: "After Dave plays 'the head' and gets down to soloing, I get a big kick out of how his left stings and punctuates like a funky 'James Brown' horn section, while his right plays in 
some sort of exotic modality." ${ }^{13}$ The whole-tone passages that can be found in this part of the improvisation are the prototype of a similar texture in the Chaconne movement of the Chromatic Fantasy Sonata.

The second part of the piano improvisation (fourth chorus) starts with repetitions of two, then three chords, which Brubeck gradually develops to more complex harmonies in bi-tonality in higher position, a technique he explored in some of his other compositions as Tritonis. ${ }^{14} \mathrm{He}$ builds the texture in block chords, continually repeating them in short rhythmic syncopations leading to the culmination. His style of polyrhythmic improvisation is best represented here through the development of independent small patterns in both hands (See Example 6b).
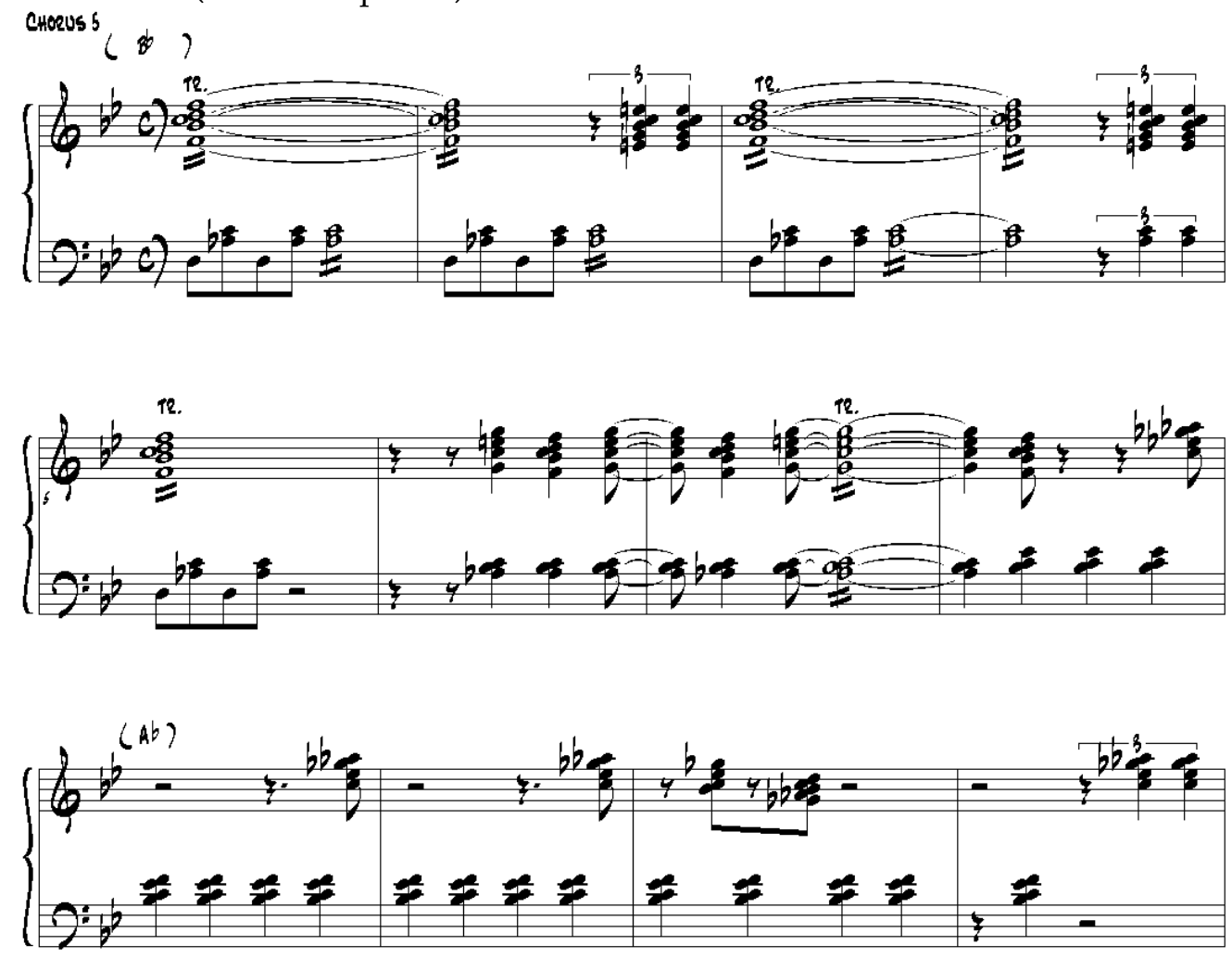

Example 6b. The first 12 measures of Fifth Chorus, transcribed by Vasil Cvetkov.

For Brubeck, this is the natural way to "shift gears" and gradually build the culmination on multiple layers. In this episode, Brubeck dramatically extends

${ }^{13}$ Trio Brubeck, Music Masters, 65102-2 (1993), liner notes.

${ }^{14}$ McFarland, Mark. "Dave Brubeck and Polytonal Jazz" Jazz Perspectives [Online], Volume 3

Number 2,( 2009). 
the range and rhythmic complexity of the texture by using multiplied voicings in combination with polyrhythmic patterns - the compositional technique later transferred to the extended sonata version. ${ }^{15}$ The dynamic drops dramatically in the ending of the piano solo, where consistently repeated $\mathrm{B} b 7 / 6$ chords pass from right to left hand down in octaves, fading like an echo.

Chris Brubeck describes the drum improvisation that follows as a "dazzling solo," adding: "Dan (Brubeck) has matured into an amazing musician, not just a 'drummer.' He throws his soul into everything he plays. . . I have played this track for friends and they can't believe it when I tell them; so I had better state in these liner notes: There is no overdubbing. All the percussion and polyrhythms are Dan-live." 16 The drum solo is followed by the recapitulation (the main theme), which brings us to a coda-like vamp of considerable length, based on two closely related chords- $\mathrm{B} b$ Major $(\mathrm{B} b 7)$ and C Major (C7), as a neighbor motion. The bass, in turn, keeps the groove pattern (Example 5b) with small variations, staying in $\mathrm{B} b 7$ harmony through the entire drum solo. This type of groove is characteristic of many solo jazz improvisations, while in this particular performance it is maintained nearly throughout the entire piece (except for mm. 13-16). At the end of the analysis, Example 7 offers a general view of the entire performance's structure.

\begin{tabular}{|c|c|c|c|c|c|}
\hline \multicolumn{6}{|c|}{ Jazzanians - 1992 recording } \\
\hline Intro & $\begin{array}{l}\text { Main Theme } \\
\text { (the Head) }\end{array}$ & Improvisation & Improvisation & $\begin{array}{c}\text { Main Theme } \\
\text { (the Head) }\end{array}$ & $\begin{array}{l}\text { Coda/ } \\
\text { Vamp }\end{array}$ \\
\hline $\begin{array}{c}\text { Drums/bass } \\
16 \mathrm{~mm} \cdot(12+4)\end{array}$ & $\begin{array}{l}\text { All- Bass, Piano } \\
\text { and Drums } \\
48 \mathrm{~mm} .(2 \times 24)\end{array}$ & $\begin{array}{c}\text { Piano Solo } \\
120 \mathrm{~mm} .(7.5 \times 16)\end{array}$ & $\begin{array}{c}\text { Drums Solo } \\
80 \mathrm{~mm} \cdot(5 \times 16+1)\end{array}$ & $\begin{array}{l}\text { All- Bass, Piano } \\
\text { and Drums } \\
16 \mathrm{~mm} .\end{array}$ & $\begin{array}{l}\text { All- Bass, Piano } \\
\text { and Drums } \\
20 . \mathrm{mm}(16+4)\end{array}$ \\
\hline $\begin{array}{l}\text { Drums solo; } \\
\text { Bass-in last } 4 \\
\text { measures- } \\
\text { ostinato motive }\end{array}$ & & $\begin{array}{c}7.5 \text { Choruses } \\
\text { Bass - vamp on } \\
\text { motive } 8+8 \\
\text { [Bb / A b]; } \\
\text { Drums continue }\end{array}$ & $\begin{array}{c}5 \text { Choruses } \\
\text { Bass - vamp on } \\
\text { B b motive }\end{array}$ & & $\begin{array}{c}\text { Vamp-last } 4 \\
\text { measures in fade }\end{array}$ \\
\hline $\mathrm{mm} \cdot 1-16$ & $\mathrm{~mm} \cdot 17-64$ & mm.65-185 & $\mathrm{mm} \cdot 186-265$ & $\mathrm{~mm} .266-281$ & $\mathrm{~mm} .282-301$ \\
\hline $0: 25$ & $1: 17$ & 3:04 & $2: 14$ & $0: 26$ & $0: 24$ \\
\hline
\end{tabular}

Example 7. The main divisions of "Jazzanians" from Trio Brubeck, Music Masters, 1993.

\footnotetext{
${ }^{15}$ Storb, Ilse and Klaus-G. Fischer. Dave Brubeck. Improvisations and Compositions. The Idea of Cultural Exchange. New York, N.Y.: Peter Lang Publishing, Inc., 1994, 71-77.

${ }^{16}$ Trio Brubeck, Music Masters, 65102-2 (1993), liner notes.
} 
The 1992 recording represents a realization which fits the best traditions of jazz trio performances: it is, perhaps, the closest of all to the original ideas attested to in the 1987 draft. After recording the "Jazzanians" tune in 1992, Brubeck reworked the piece and arranged it for solo piano. This version was published in 1993 by CCP/Blewin, Inc. (Example 8). As mentioned in the Overview, in this published version Brubeck made use of the 12-tone countersubject found in the 1988 Fugue draft, but the difference between the first published and the previously recorded versions was not limited to the insertion of the 12-tone theme. ${ }^{17}$ Working on the new version Brubeck added new material, which extended the composition and changed the time signature.

Brubeck marked the score "Fast Waltz $\rfloor_{.}=60$ ", replacing the $4 / 4$ meter with the $3 / 4$ meter. The piece begins with the 12 -tone theme followed by the fast-waltz version of the "Jazzanians" tune (See Example 8).

${ }^{17}$ See Tom Roed's At the Piano, mm.1-32, and mm.81-119. 


\section{JAZZANIANS}
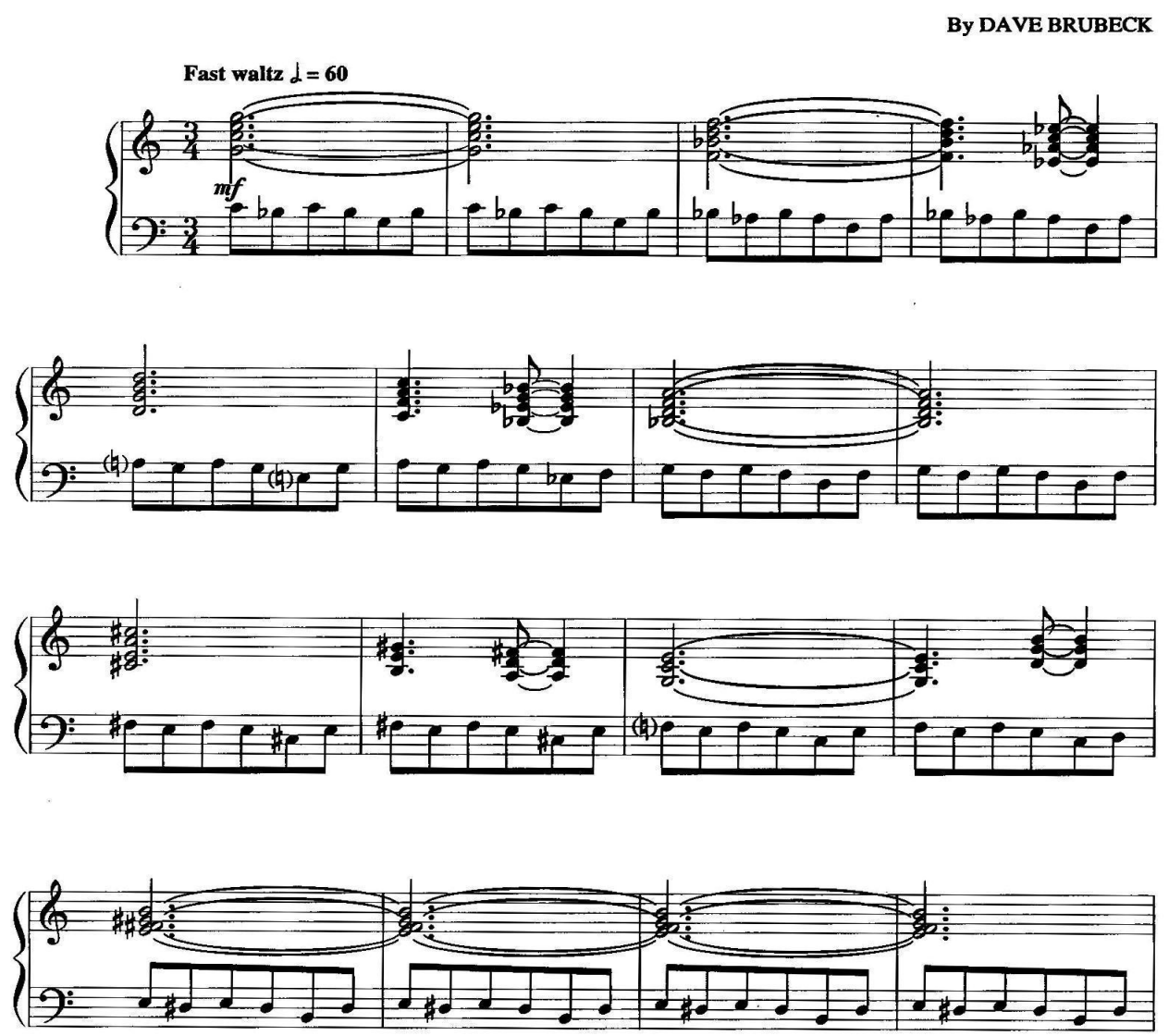

Example 8. Tom Roed's publication At the Piano, 12-tone theme, mm. 1-12.18

The form of the new version is $\mathrm{ABCB}$ and coda, having the following overall structure: $\mathrm{A}$-the 12 -tone theme; $\mathrm{B}$-the main "Jazzanians" theme; $\mathrm{C}$-a new theme; B-the return of the main "Jazzanians" theme; and an 8-measure coda. This published version was never recorded, perhaps because Brubeck was already working on a version that would become a composition in the album Jazz Sonatas, released in 1994, which, in turn, would become later the Chaconne movement of the Chromatic Fantasy Sonata.

\section{THE SECOND REALIZATION, RECORDED IN 1994}

The next recorded realization of the "Jazzanians" tune is represented by the Quintet Sonata, which was performed by the chamber ensemble An Die Musik

18 “Jazzanians," Tom Roed's publication At the Piano 
as part of the Jazz Sonatas album, released by Angel Records on March 15, 1994. The subtitle of the sonata: "inspired by J. S. Bach," makes clear the influence of the Baroque master. The history of the "Quintet Sonata" can be traced back to July 23, 1988, when Constance Emmerich (the pianist of An Die Musik) in a letter to Brubeck commissioned a work for her group. A year later Brubeck presented a detailed plan for a composition called Chromatic Fantasy Sonata, which was originally conceived as a variation cycle. Nevertheless, the 1994 recording included only the last movement "Chaconne," while the other two movements, "Allegro Molto" and "Chorale," finished the same year, were published by Warner Brothers as part of a piano arrangement version.

At the time, the group An Die Musik was known internationally as American Chamber Musicians and "had been acclaimed for its artistry throughout the United States and Europe." ${ }^{19}$ Founded in 1976, the ensemble took its name from Schubert's song in praise of music. The unique combination of oboe, string trio, and piano allowed both the ensemble and composers to explore a huge range of repertoire-from classical and romantic to contemporary music literature. The ensemble was famous for commissioning and premiering works by American composers. It performed at the leading music series in New York City and in the major musical capitals of Europe. The purpose of the Jazz Sonatas project was revealed by Constance Emmerich at its premiere in the Merkin Concert Hall in New York City on November 13, 1994.

The piece [Quintet Sonata] is part of the project for the next season ... It's a crossover series of jazz composers who are influenced by classical, and classical composers who are influenced by jazz.... A friend of ours suggested ... "Which composers were of great inspiration to composers as they developed as young people?" And the composers participating in that project are: Dave Brubeck, Israel Letterman, and Andre Previn...it's an ongoing project. And Brubeck's inspiration was Bach. ${ }^{20}$

The New York concert program and the album of new music included pieces by the following composers: Brubeck, Roland Hanna and Dick Hyman. The album's producers explained these choices as "the result of our search for

${ }^{19}$ Jazz Sonatas, Angel Records, CDC 5-55061-2-2 (1994), liner notes.

${ }^{20}$ Constance Emmerich's introduction at the premiere in the Merkin Concert Hall in NYC, November 13, 1994 (transcribed from Brubeck's private recording). [Box 4B.97.40.: An Die Musik: Master Tape] Brubeck Collection, Holt-Atherton Special Collections, University of the Pacific Library. Copyright (C) Dave Brubeck. 
jazz composers who are also outstanding instrumentalists." ${ }^{21}$ In a letter to Constance Emmerich, Brubeck stated that the fusion of the jazz idiom with Bach's influences was the motivational factor in the development of this work: "[t]his [composition] (Chaconne) seems to me to be more reflective of a jazz musician writing for An Die Musik than the other movements. I have the feeling this will be the piece you will program the most..."22 The composition displays the influence of Brubeck's jazz quartet background (particularly his five albums from 1959 to 1965-Time Out, Time Further Out, Countdown: Time in Outer Space, Time Changes, and Time In). These albums encompassed Brubeck's most radical experiments in metrical diversity, and became characteristic of his later classical and jazz compositions.

The analysis of the composition shows that both the quintet (for An Die Musik) and the quartet versions share the same structure with only minimal changes in the orchestration (a version written for the Brodsky Quartet that will be discussed later). It also demonstrates that Brubeck was familiar with arranging material for different types of ensembles. A comparison of all of the different scores shows that he uses the piano part of the quintet version to create the basic frame for the above- named and later arrangements. Stylistically, in the An Die Musik's version, the piano part plays the main role in keeping the motoric drive. In addition, the bass voice of the left hand is doubled, with minor changes in the cello part. The melody in the top voices is consecutively carried by the oboe and violin with the shift between the instruments creating a conversational effect. In addition, the bass voice of the left hand is doubled, with minor changes in the cello part. The melody in the top voices is consecutively carried by oboe and violin, with the shift between instruments creating a conversational effect. For example, in the Introduction and the 12-tone theme (mm.85-100) in the "Jazzanians" section, the oboe plays the top voice, while the violin leads the same voice in the rest of the variations. The performance sound is "classical," very straight and without any jazzy intonations, thus having the flavor of a chamber orchestra style. Moreover, the sectional divisions are clearly recognizable.

The Quintet Sonata is a long (325 measures) and complex composition, in which the middle section, with its "Jazzanians" theme, serves as a core, while the other parts of the movement provide elaboration. The nearly continual presence of the main ostinato motive assures a unifying background for the

${ }^{21}$ Jazz Sonatas, Angel Records, CDC 5-55061-2-2 (1994), liner notes.

${ }^{22}$ Constance Emmerich, notes to Kennedy Center program (1994), 19. [Box Programs, 1994, 1.F.18.2: An Die Musik] Brubeck Collection, Holt-Atherton Special Collections, University of the Pacific Library. Copyright (C) Dave Brubeck. 
movement. However, the combination of diatonic and chromatic approaches gives the piece a unique flavor, which in its turn furthers the sonata's largescale narrative, thanks to the many motivic connections. Brubeck wrote it as a set of continuous variations with a great variety of tempos, meters, and rhythms, with his signature 5/4 meter making its appearance in the third section (mm. 235-262). The movement has three main divisions (See Example 9) with different characters and thematic material, but the main ostinato motive provides a motoric feel throughout the entire piece. The sections are composed in three different tempos, gradually increasing from $d=96$ to 120 to 160. Moreover, Brubeck ends each section in a slower tempo or extends the slower tempo into the next section. Example 9 presents the overall formal design of the composition.

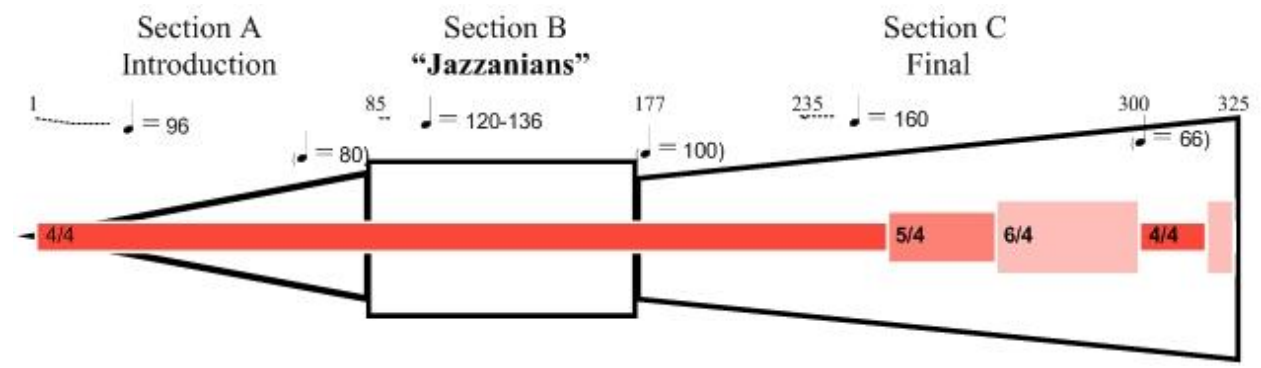

Example 9. Diagram of the textural shape of the Quintet Sonata.

The piece begins with a short introductory passage in the form of the distinctive "Jazzanians" ostinato motive in octaves. In this quintet arrangement, violin, viola, cello and piano collaborate to establish the motoric feel of the beginning (see Example 10, mm.1-3). Brubeck gives this motive a double purpose: it serves as an introductory bass line and as melodic material found later in the piece. 


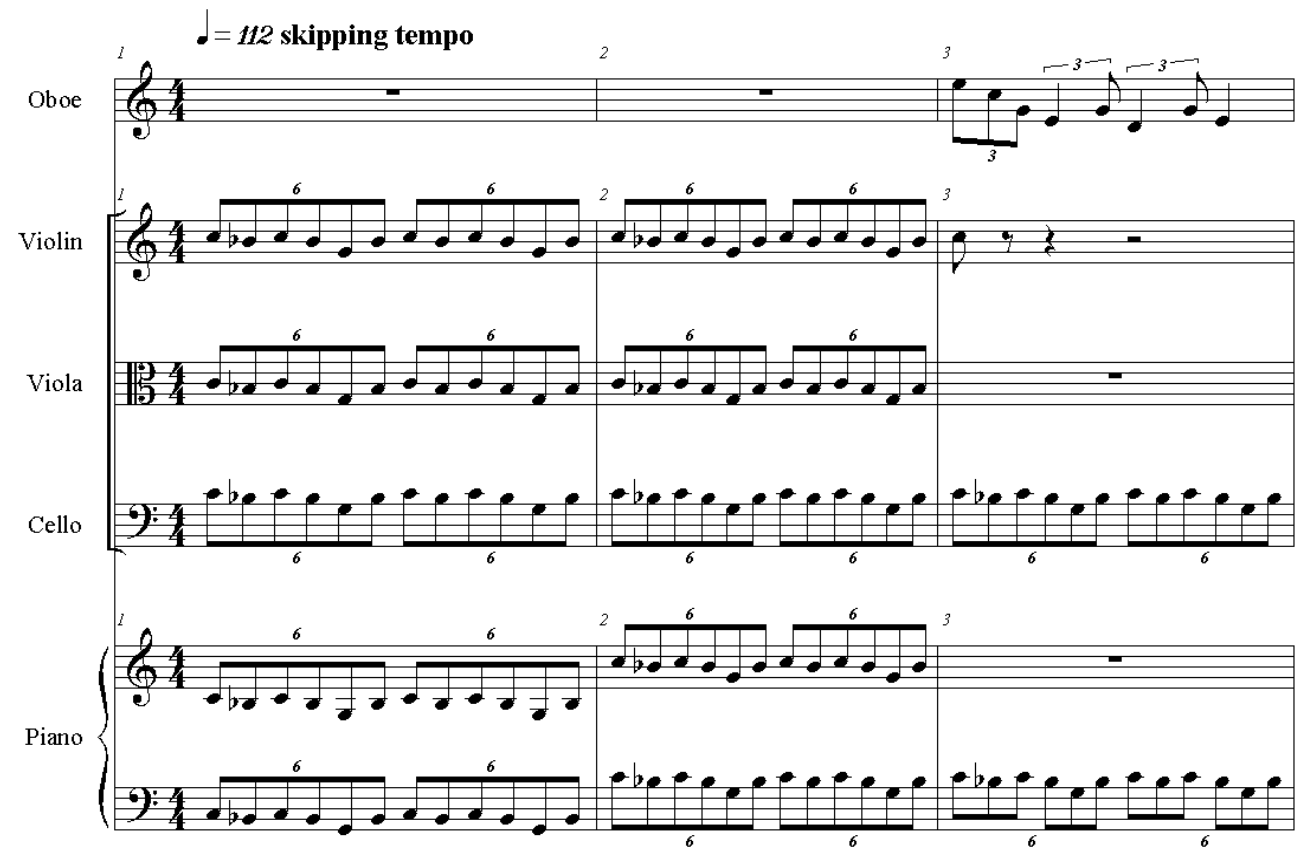

Example 10. Ostinato motive, mm. 1-3 of the Quintet Sonata. ${ }^{23}$

The entire composition is firmly based on the tonal center of $\mathrm{C}$. The overall tonal center of $\mathrm{C}$ is reestablished at the beginning of Variation 3 (m.53), where the first example of a citation of the jazz tune occurs, a descending melodic tetrachord in an extreme upper register $(\mathrm{C}, \mathrm{B} b, \mathrm{~A}, \mathrm{G}$ in $\mathrm{mm}$. 53-56). Example 11 shows that, in $\mathrm{m}$. 54, the upper line is accented offbeat, while in the following measure-doubled in thirds in violin, oboe, and the top voice of the piano part-it descends by whole tones $(\mathrm{E}-\mathrm{D}-\mathrm{C}-\mathrm{B} b$ in m. 55), exactly as in the "Jazzanians" theme.

${ }^{23}$ [Quintet Sonata] Brubeck Collection, Holt-Atherton Special Collections, University of the Pacific Library. () Dave Brubeck 


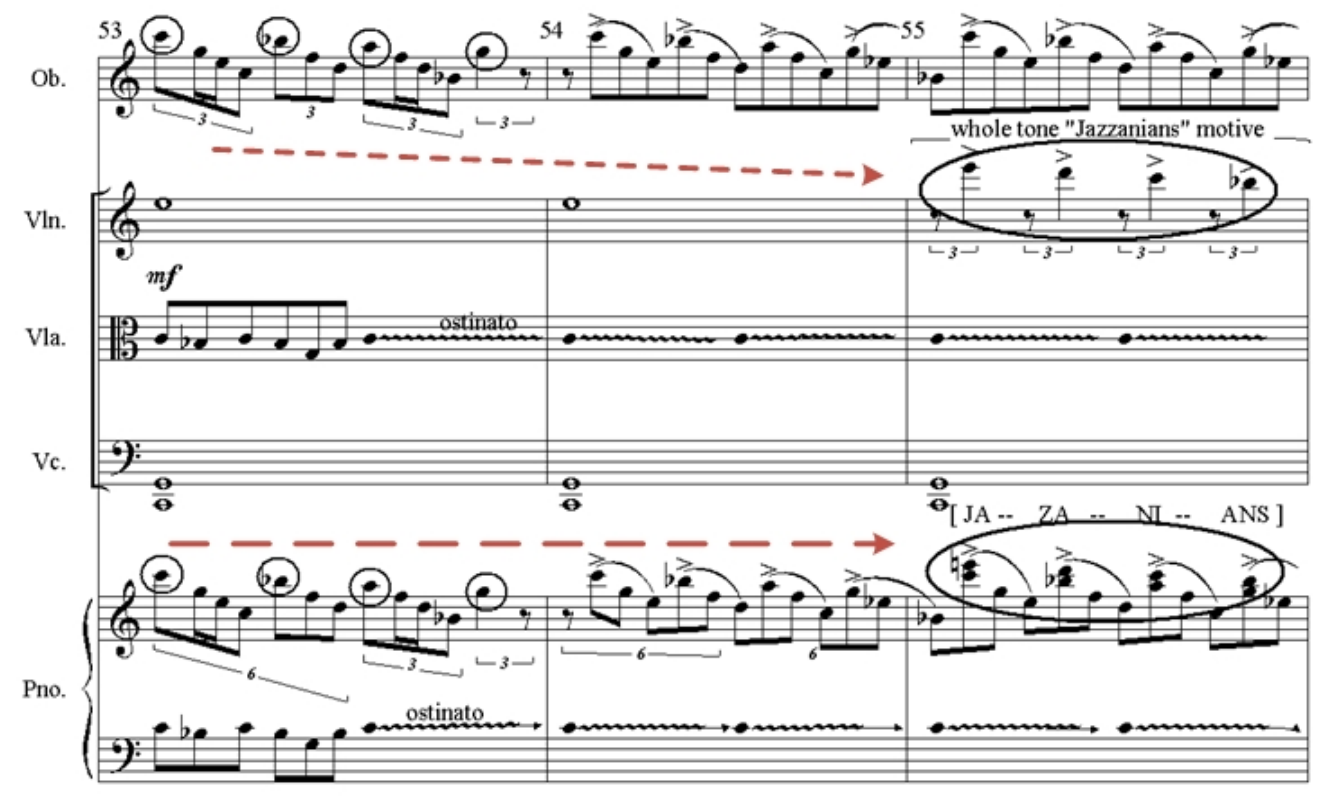

Example 11. Variation 3, mm. 53-55 of the Quintet Sonata, whole-tone "Jazzanians" motive [e-d-c-bflat].

The central B section of the Quintet Sonata, mm. 85-176, is very melodic and presents the "Jazzanians" theme that appears through the entire composition. Based on the structural analysis, we can state that the B section ("Jazzanians") represents the core of the composition around which the outer sections were created. The section consists of three statements of the "Jazzanians" theme and two variations. The "Jazzanians" theme is presented here in the restored original $4 / 4$ time signature from the trio-recorded version. Nevertheless, Brubeck employs here the same 12-tone theme as in the published piano version while the extended presentation of the original "Jazzanians" tune offers ground for two variations that close the section.

As stated above, the overall form of the composition is a collection of different motivic ideas presented and developed in an original manner. Brubeck saves a complete statement of the "Jazzanians" tune for the center of the movement (Section B), and develops the other sections from ideas drawn from the central section. This central section consists of thematic material as follows: in $\mathrm{m} .85$ the 12 -tone theme ( $2 \times 8$ bars) begins; in m.101 the original theme that begins with the whole-tone "Jazzanians" tetrachord (Brubeck's original tune, $3 \times 8$ bars) emerges; a sequential continuation ( $2 \times 8$ bars) begins in m.127. This entire section is based on the 1993 published version of "Jazzanians." 


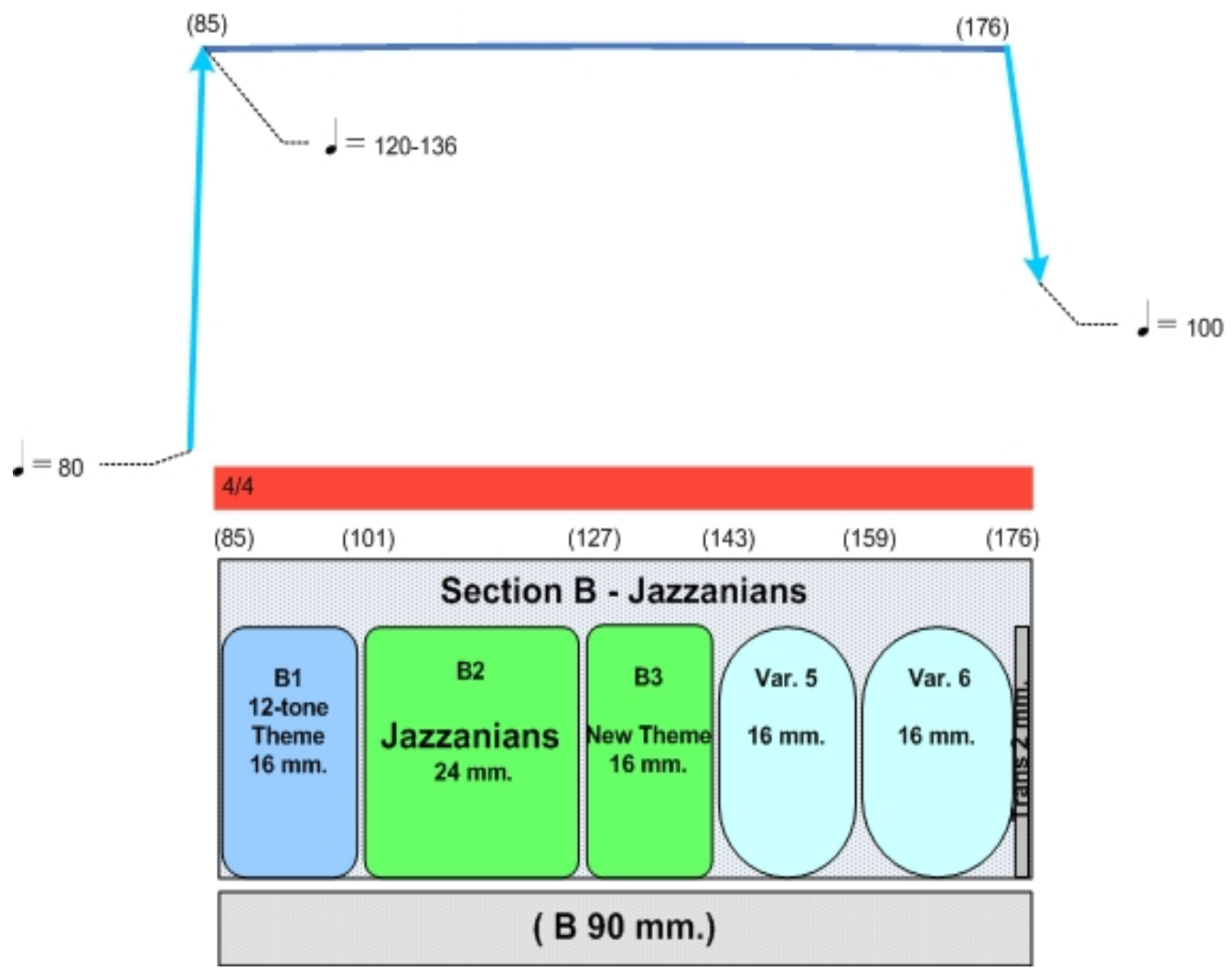

Example 12. Measures 85-176, Section B-“Jazzanians."

As the voice-leading reduction of Example 13b shows, the diatonic construction of the 12-tone theme (diatonic heptachord plus diatonic pentachord; see Example 13a) is supported by a descending bass represented by the ostinato motive anchored with salient harmonic perfect fifths in mm. 85, 89 , and 92.

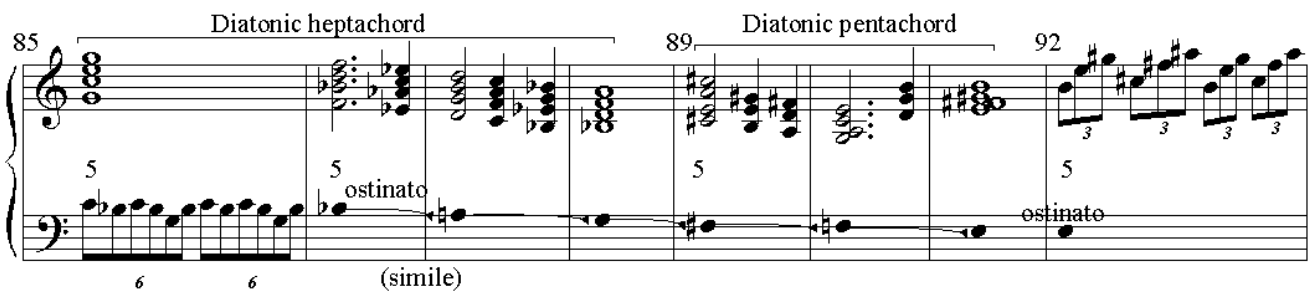

Example 13a. Chaconne, the 12-tone theme, mm. 85-91. 


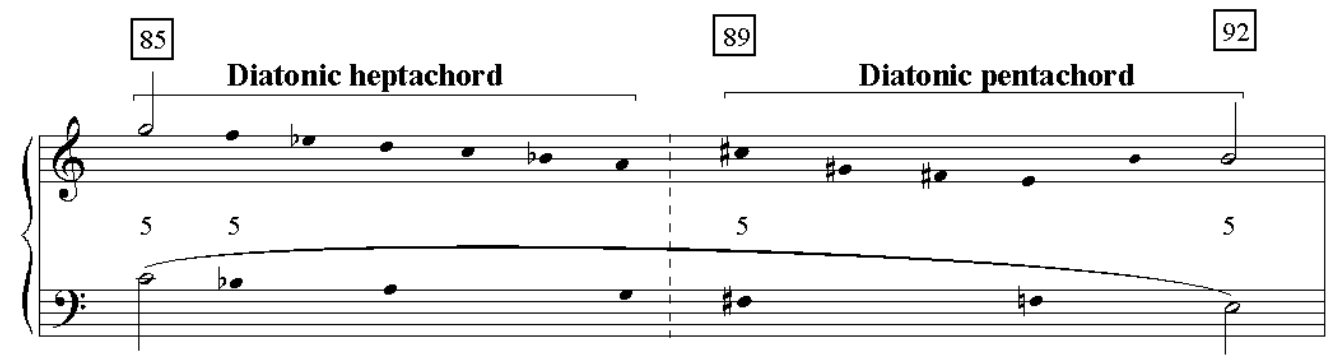

Example 13b. Voice-leading reduction of the 12-tone theme, mm. 85-91.

The first statement of B1 (the 12-tone theme, mm. 85-92) confirms the overall tonal center of the composition. A transposed restatement, mm. 93100 , begins on $\mathrm{E} b$ and serves as preparation for the presentation of the "Jazzanians" theme, which begins with a statement of the "Jazzanians" tetrachord in its original key of $\mathrm{B} b$ (mm. 101-125). After a transposed restatement beginning a whole step lower (mm. 109-116), a final cadential phrase returns to $\mathrm{B} b$ (mm. 117-124). The neighbor motion ( $\mathrm{B} b-\mathrm{A} b-\mathrm{B} b)$, traced by the bass in these three eight-bar phrases, recalls the same neighbor motion on a smaller scale in the original "Jazzanians" theme. Furthermore, as seen in Example 14, in mm. 105-109, the original "Jazzanians" motive is repeated in diminution with embellishment.

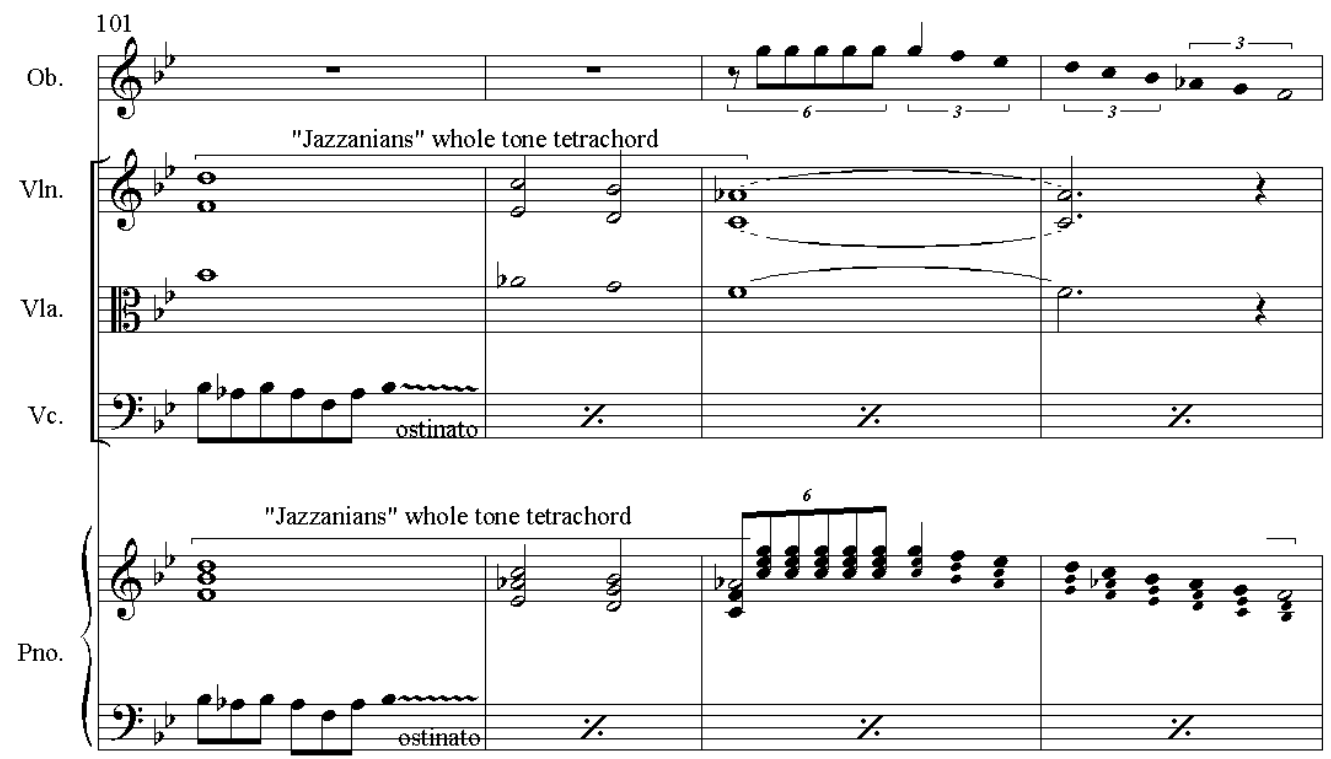




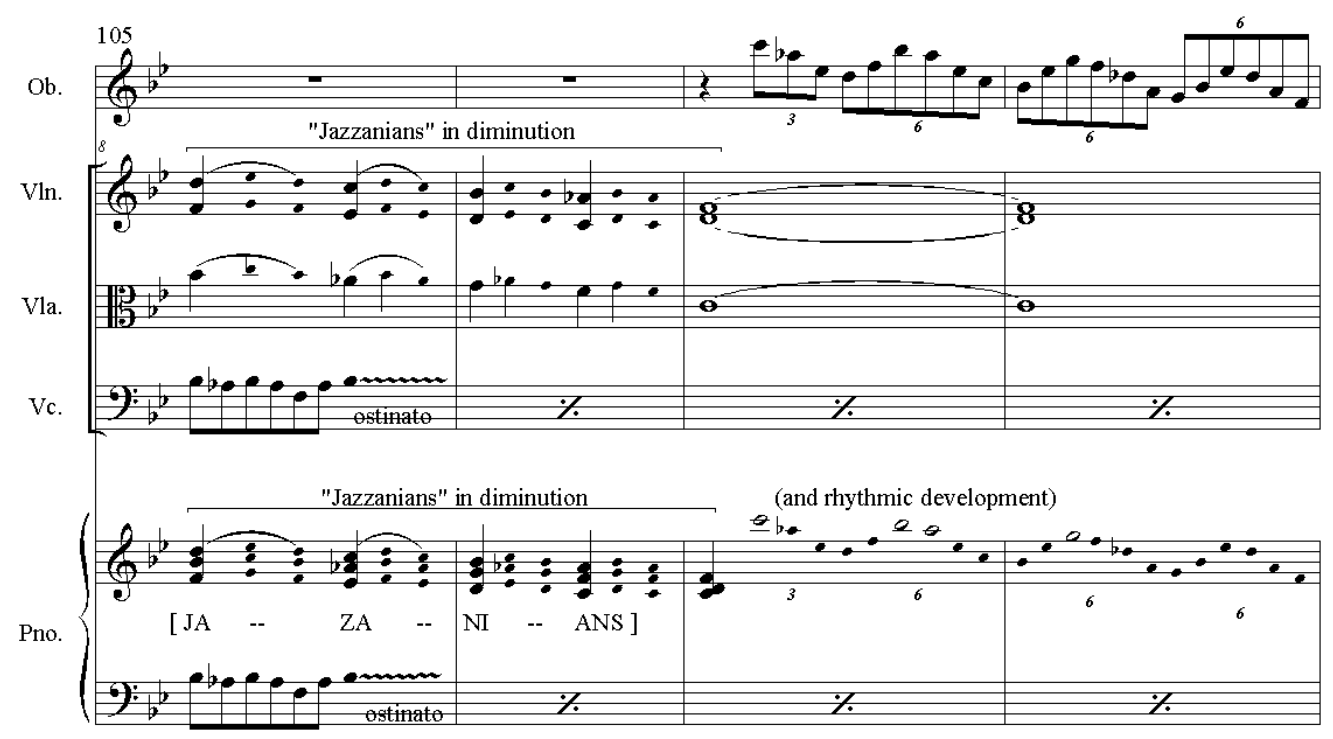

Example 14. Quintet Sonata, "Jazzanians" theme, mm. 101-109.

The third part of this section (B3, mm. 127-142) also represents symmetrical divisions ( $8+8$ measures). Beginning in $\mathrm{B}$ major, the music continues a half step higher in $\mathrm{C}$ major at $\mathrm{m}$. 135, reaching and prolonging an $\mathrm{F}$ dominant seventh harmony in $\mathrm{m}$. 139-142. The arrival on $\mathrm{F}$ is significant because it is the dominant of the returning $\mathrm{B} b$ in the variation that follows.

Variations 5 (mm. 143-158) and 6 (mm. 159-176) represent the last part of Section B. Both variations contain elements transferred from Brubeck's jazz improvisations on "Jazzanians" (Trio Brubeck). For example, he uses the same chords, $\mathrm{B} b$ and $\mathrm{A} b$, for eight measures each, as in the Trio Brubeck recording. However, in these variations Brubeck incorporates many elements of the thematic material from Section A: motives and parts of motives, syncopations, and varied rhythmic patterns. The variations resemble written-out jazz improvisations. As shown in Example 14, Brubeck creates multiple polyrhythmic patterns, displacing the strong beats in the upper voice by using three-, four- and six-note groups and augmentation over the sextuplets of the ostinato motive in the bass line. For instance, he creates hemiola and cross rhythms by accenting every fourth eighth note starting with the downbeat of m. 143, then every third eighth in mm. 147-148, and by using offbeat and augmented triplets from m. 149 on. 


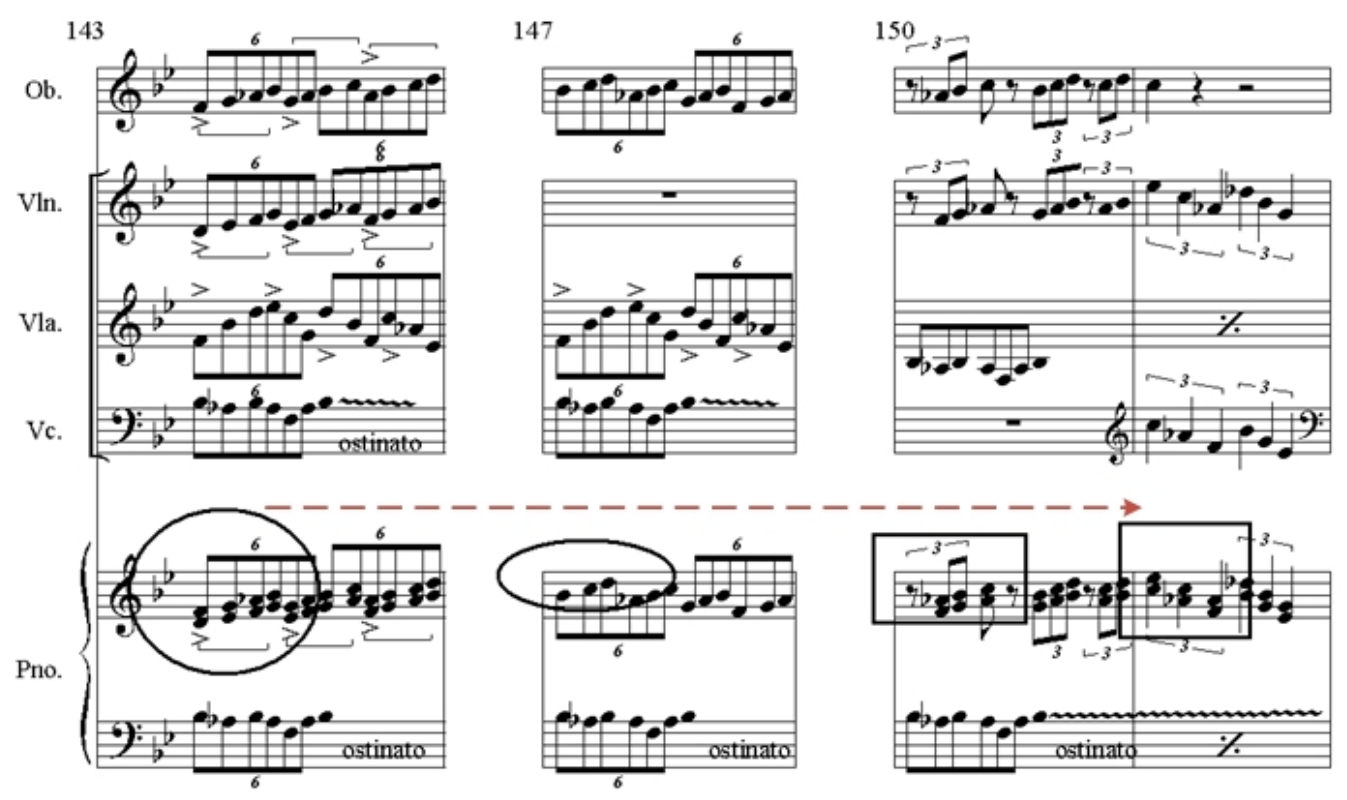

Example 15. Section B, Variation 5, polyrhythmic development.

The voice-leading reduction shown in Example 16 illustrates the importance of the deep middle-ground motion from C (m. 85) to $\mathrm{B} b(\mathrm{~mm}$. 101-117 and 143-175) and back to $C$ (at Variation 7, m. 177). In fact, the entire central portion of the composition can be heard as a large-scale neighboring motion, with the central presentation of the "Jazzanians" theme (in its original key of $\mathrm{B} b$ ), framed by strong reassertions of the movement's tonic C. This whole-step motion is of course strongly present in both the ostinato and in the motivic tetrachords of the B section's themes. On the more local level, Variations 5 and 6 ( $\mathrm{mm}$. 143-176) feature the same $\mathrm{B} b-\mathrm{A} b-\mathrm{B} b$ neighbor motion as the original "Jazzanians" theme.

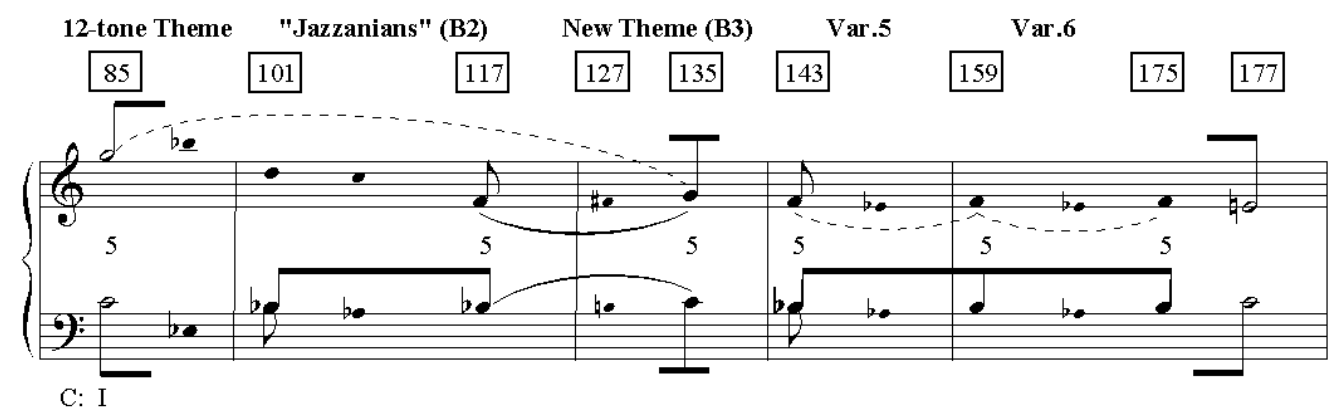

Example 16. Voice-leading reduction, mm. 85-177. 
Of the three sections in the composition, the third (Section C, mm. 177$325)$ is the longest and the most complex, consisting of three subdivisions. The first subdivision of the section consists of three variations (Variations 7, 8, and 9). Variation 8, mm. 200-216, introduces a new lyrical character. The top voice [F-E-D-C] is a new variant of the descending Lament and "Jazzanians" tetrachords; however, the first iteration (mm. 198-206) is presented as four two-measure phrases with a triplet rhythm. In mm. 207-213, Brubeck adds an arpeggiated bass to thicken the contrapuntal texture. As Example 17 illustrates, besides developing the triplet rhythm that begins Variation 8 through augmentation, he adds embedded "Petrushka" harmonies. ${ }^{24}$ The tonal orientation of the variation is not stable, and the bass line continues to move chromatically through the whole variation.

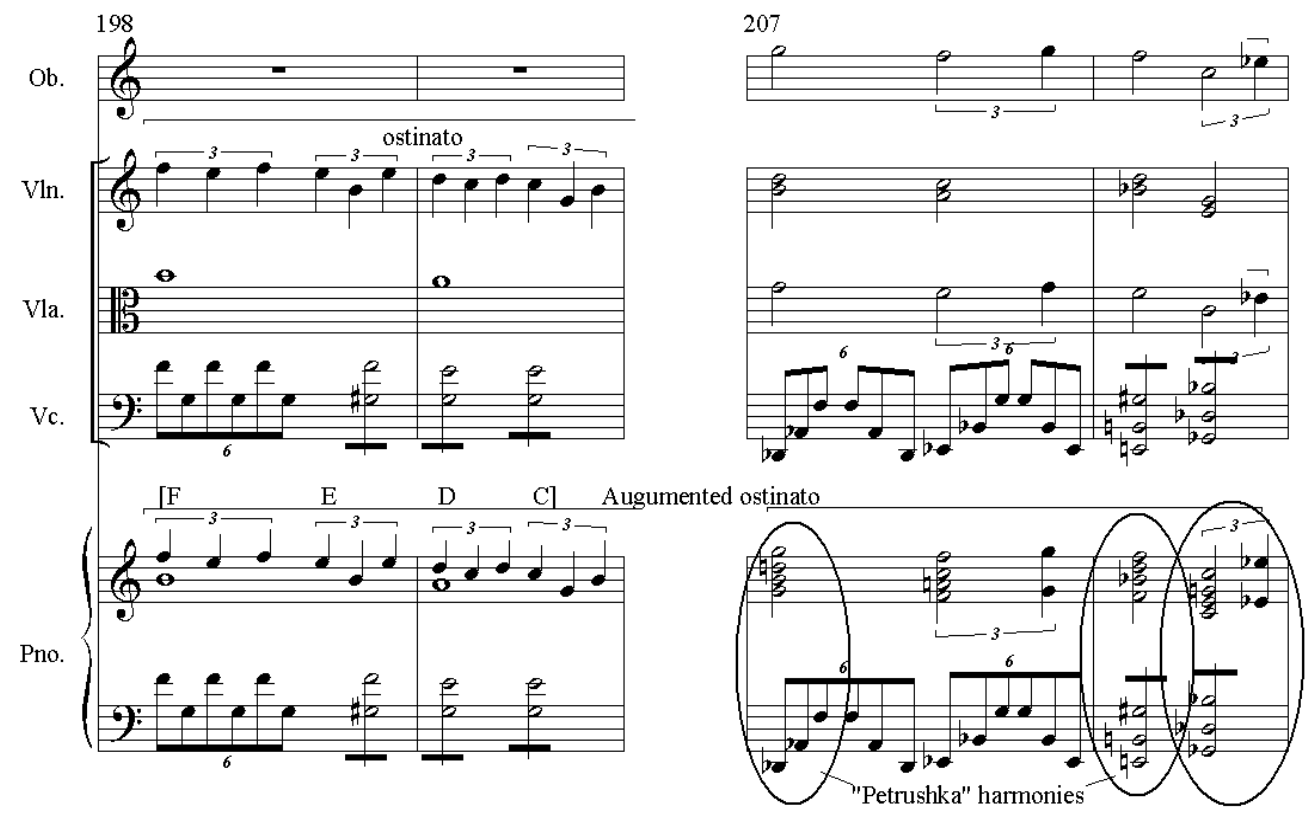

Example 17. Development of ostinato motive, Variation 8, mm. 198-199 and 207-208.

The second subdivision, $\mathrm{mm}$. 229-290, also consists of three variations (Variations 10, 11 and 12). It contains Brubeck's trademark 5/4 time signature, and has a character derived from the previously mentioned Time Changes period. This division begins in $4 / 4$ meter (m. 229), contains the tempo marking $J=160$ at $\mathrm{m}$. 235, the fastest of the entire sonata, and represents a

\footnotetext{
24 "Petrushka" chord refers to a specific polychordal construction. The author uses it in this article to define any combination of two major triads whose roots are a tritone apart or a sonority that is inversionally related to such a polychord.
} 
large-scale motivic development of the ostinato motive, which occurs throughout the entire unit. To achieve the motivic development, Brubeck recomposes the ostinato motive in 5/4 meter for Variation 10, then in 6/4 meter for Variations 11 and 12.

The first part of the last subdivision of this section, mm. 291-300, bears the tempo marking, "Tender, slower," while maintaining the 6/4 meter. This part-the "Bach" section-contains many internal tempo and dynamic changes, which create an improvisational mood. It represents Brubeck's liturgical, spiritual inspiration, and aptly represents his dedication to his favorite composer as it culminates with a correctly spelled Bach signature in $\mathrm{m}$. 300. In the next passage, as shown in Example 17, Brubeck develops four different contours of the $\mathrm{B}-\mathrm{A}-\mathrm{C}-\mathrm{H}$ motive, reintroducing the rhythm of the head motive from the first 12-tone theme of his "Unscholarly Fugue" $(d\rfloor d)$, which is supported by an ascending chromatic accompaniment in parallel sixths. Moreover, the last notes of these motives form the whole-tone "Jazzanians" motive [A G F Eb] and the "Lament" tetrachord [G F Eb D] ending at $\mathrm{m}$. 299. This fact confirms Brubeck's compositional purpose of creating diatonic motives strongly connected with the "Bach" signature, which provides a strong contrast to (and, in a sense, a resolution of) his chromatic orientation in the first theme.

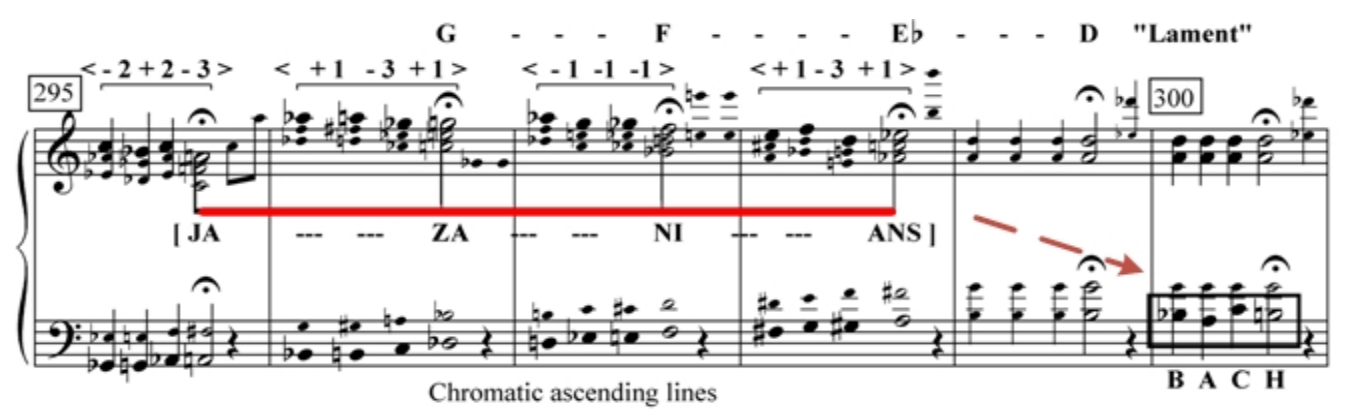

Example 18. Quintet Sonata [Chaconne movement], "Jazzanians" in the "Bach" section, mm. 295-300. ${ }^{25}$

In a letter to John Salmon, Brubeck explains his intentions: "throughout the various motifs I spelled out BACH's name with one letter purposefully wrong until I finally at the end of the movement spelled it correctly in the German

\footnotetext{
${ }^{25}$ The following examples are from the piano-transcribed score of the composition: Gail Lew and John Salmon eds., Seriously Brubeck. Original Music by Dave Brubeck (Warner Bros. Publication, 2003), 147-149.
} 
spelling ... BACH."26 Part two of the last subdivision, mm. 301-319, has a Rubato espressivo $\mathrm{J}=66$ tempo marking in $4 / 4$ meter; its character is transitional. Example 19b provides a graphic analysis of mm. 301-308, a conglomerate of alternating and combined variant forms of the main motives. The ostinato motive is presented in parallel thirds on the first two beats of $\mathrm{m}$. 301 and is followed by a chromatic line in the bass, which supports a deformed version of the "Jazzanians" tetrachord in the upper voice through the emphasized fermata notes in mm. 301-302.
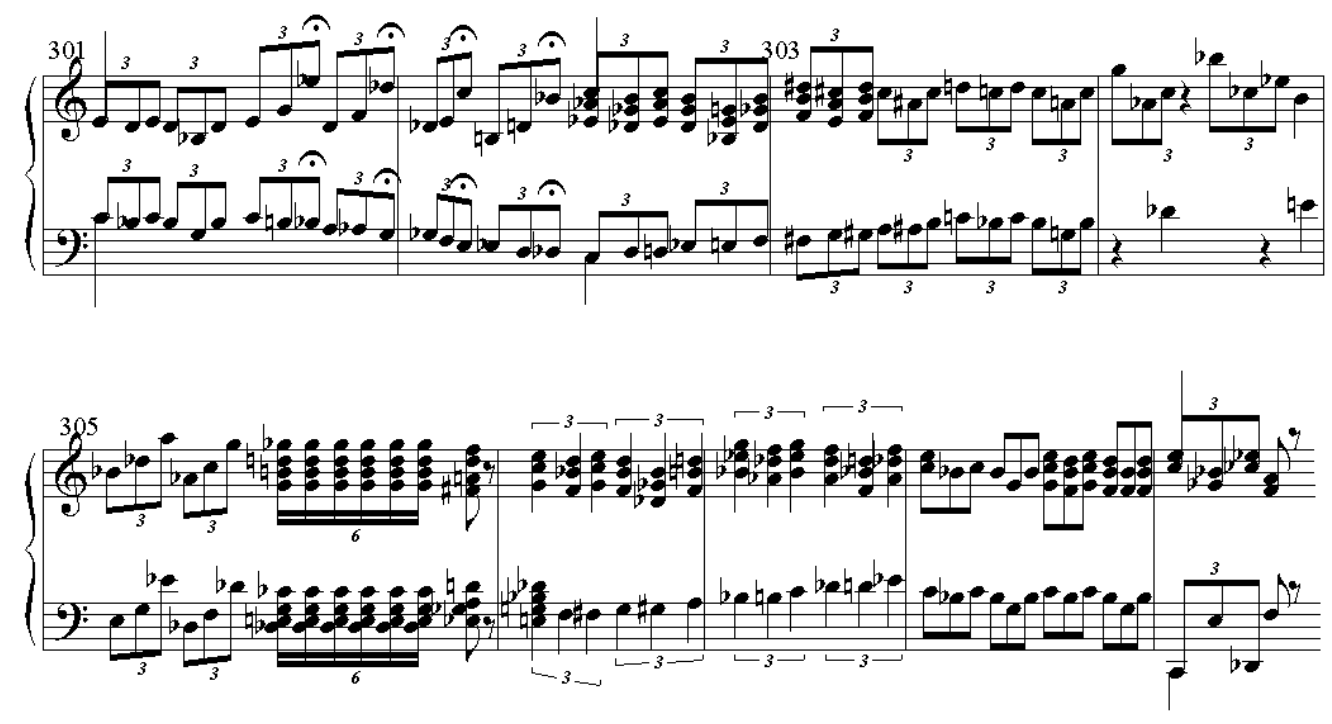

Example 19a. Piano transcription, mm. 301-309

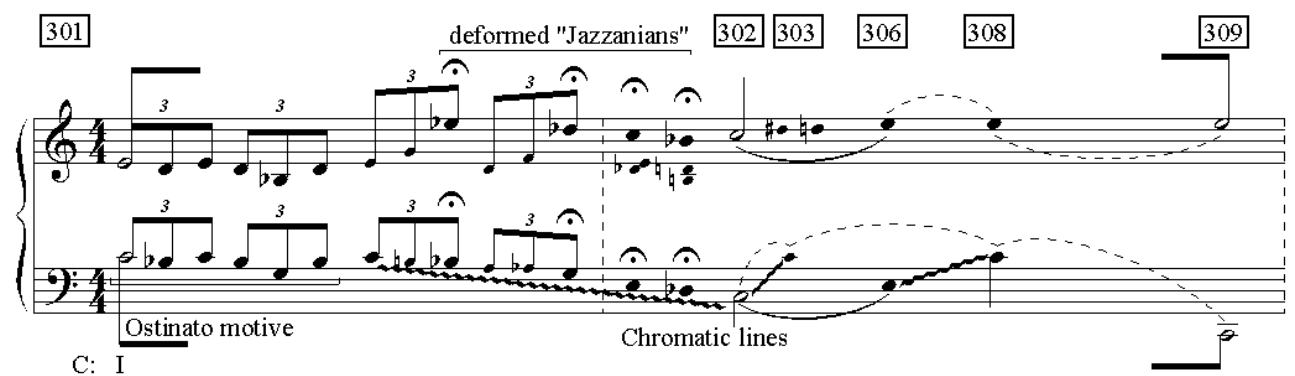

Example 19b. Voice-leading reduction, deformed "Jazzanians," mm. 301-309.

\footnotetext{
${ }^{26}$ From Dave Brubeck to John Salmon, Oct. 18, 2003. [Private correspondence, Brubeck was writing about the Chaconne.]
} 
The Quintet Sonata represents a brilliant example of compositional technique subordinated to inspiration, although the source of inspiration in this particular case was, in a sense, "chosen." The process of writing a piece "inspired by J.S. Bach" for a classical ensemble, based on the "Jazzanians" tune, yielded a realization so different from the jazz trio version that, if it were not for the ostinato motive and the "Jazzanians" theme itself, the connection would be hard to trace. No doubt, the 1993 unrecorded version represents an important link in following the process of transformation from one recorded version to another, which is why a short presentation of it is appropriate in this chapter. As we already know, what seemed to be a definite realization in 1994 was only the continuation of a long journey, in which the "Quintet Sonata" played an important role.

\section{THE THIRD REALIZATION, A LIVE RECORDING IN 1995}

The Brubeck Collection at the University of the Pacific in California includes evidence attesting to the fact that, after the premiere performed by An Die Musik in 1994, Brubeck was planning on creating an orchestral version of the same composition. A manuscript of a full orchestral score (not dated) bears the heading III Fantasy Chromatique. However, there is no evidence that this version was ever performed or recorded. This may be explained by the fact that Brubeck reworked this score into a version that became a short orchestral show tune arranged for his jazz quartet and a symphony orchestra. Four concert programs in the Collection confirm that there were performances of this later orchestral version. 


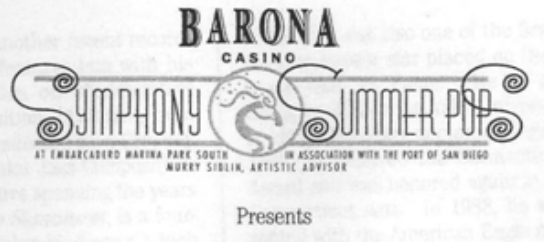

"The Dave Brubeck Quartet - The Jatz Legend...Luve!"

Friday, August 25, 1995 at 7:30 p.m.

Saturday, August 26, 1995 at 7:30 p.m.

Embarcadero Marina Park South

Dave Brubeck, piano

Russell Gloyd, conductor

Chris Brubeck, electric bass Darius Brubeck, piano

Matthew Brubeck, cello Dan Brubeck, drums

Bobby Mititello, alto sax/flute

$\begin{array}{ll}\text { BRUBECK } & \text { "Summer Music" } \\ \text { BRUBECK } & \text { "Three to Get Ready" } \\ \text { BRUBECK } & \text { "Lullaby" } \\ \text { BRUBECK } & \text { "Cassandra" } \\ \text { BRUBECK } & \text { "Theme from June" } \\ \text { BRUBECK } & \text { "Jazzanians" } \\ \text { BRUBECK } & \text { "The Duke" } \\ & \text { Intermission } \\ \text { BRUBECK } & \text { "Cathy's Waltz" } \\ \text { BRUBECK } & \text { "The Basie Band is Back in Town" . } \\ \text { BRUBECK } & \text { "Koto Song" } \\ \text { DESMOND } & \text { "Take Five" } \\ \text { BRUBECK } & \text { "Blue Rondo a la Turk" }\end{array}$

Generousty SPONSORED by DANIELSON TRUst Company

The San Diego Symphony Orchestra is funded in part by the National Endowment for the Arts, Calffornia Arts Council, City of San Diego Commission for Arts and Culture, and the County of San Diego.

The use of cameras and recording equipment is prohibited.

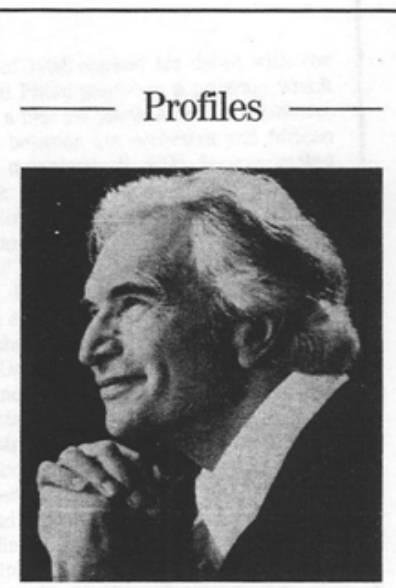

When the legendary DAVE BRUBECK was first heard on recordings in 1949, his distinctive harmonic approach and daring improvisations generated excitement with both critics and jazz aficionados. His group won both the Critic's Poll and the Reader's Poll the same year in DownBeat Magazine. The Dave Brubeck Quartet with Paul Desmond became the sound that identified an era. Their recordings and concert appearances on college campuses in the 50's introduced jazz to thousands of students. They were in demand in jazz clubs across the country, and toured in "package shows" with Charliê Parker, Dizzy Gillespie, Stan Getz and other musicians of the bop era. The Dave Brubeck Quartet won the first jazz poll conducted by a black newspaper, The Pittsburgh Courier. By 1954, Brubeck's popularity was such that his picture had appeared on the cover of Time Magazine and he was recording for a major label. In 1960, the Dave Brubeck Quartet, with Paul Desmond, Eugene Wright and Joe Morello, released their first experiment in odd-metered rhythms. The album, Time Out, and its singles, "Take Five" and "Blue Rondo a la Turk," became the first in modern jazz to "go gold."

Still touring and recording after more than fifty years in the business, Brubeck's newest releases, Late Night Brubeck and Nightshift, were recorded live at The Blue Note in New York in October of "93 by Telarc. His piano solo album, Just You, Just Me soared in the jazz charts soon

Example 20. Concert program, San Diego Symphony Orchestra concert, August 25, $1995 .{ }^{27}$

27 [Concert program, San Diego Symphony Orchestra concert, August 25, 1995] Brubeck Collection, Holt-Atherton Special Collections, University of the Pacific Library. (C) Dave Brubeck 
The most important concerts of this series took place on December $2^{\text {nd }}$ and $3^{\text {rd }}$, 1995, when Dave Brubeck and all of his sons-Darius, Chris, Matthew and Danny-accompanied by the London Symphony Orchestra, celebrated Brubeck's $75^{\text {th }}$ birthday with two "Birthday Bash" concerts. The new orchestral version of "Jazzanians," conducted by Russell Gloyd and performed on the piano by Darius Brubeck, proved to be one of the brightest tunes in the program..$^{28}$ Darius was specifically introduced as piano soloist on the "Jazzanians."

With a clear, formal frame and a classical orchestration, this version is one of the best examples of style crossover in Brubeck's body of work, as his private recording of the concert clearly demonstrates. ${ }^{29}$ Here, classical elements commingle with the very active role of jazz instruments (Brubeck Jazz Quartet), which are designated as improvisers in the large middle section. There is no published score of this performance. Forced to make a transcription, I stumbled across an interesting fact: this version is 325 measures long, the same as Quintet Sonata, the length of the recorded performance being 8 minutes and 17 seconds. Unfortunately, I found no evidence indicating whether this particular number of bars was determined by Brubeck's sense of form or pure coincidence. Borrowing form principles from the jazz trio version, Brubeck uses here a 24-measure theme with an extended improvisational section for alto sax, piano and drums.

The performance begins with a twenty-measure introduction of the ostinato motive: the first four measures have just solo strings; then the entire orchestra unfolds with pedal notes for a sixteen-measure free saxophone solo improvisation supported by electric bass and drums.

The exposition, or "head," contains twenty-four measures, in which the main theme is carried by the full brass section and alto sax. The ostinato motive is placed in the string section, while the low brass is given some counter melodies. Afterwards, there are three sixteen-measure alto sax solos in which the strings take the main melody in octaves and repeat it as background for the exotic, virtuoso alto saxophone solo of Bobby Militello. As in the jazz trio version, Chris Brubeck maintains the same bass groove pattern, presented in Example $5 \mathrm{~b}$, throughout the entire performance. The piano improvisation can

\footnotetext{
${ }^{28}$ London Symphony Orchestra: A Brubeck Birthday Bash, Dec 2-3 (DB, Bobby Militello, Chris, Matthew, Danny). [Box. 19: PROGRAMS, 1995 Ms4].

${ }^{29}$ Private recording of the Birthday Bash concert at London, Dave Brubeck Family, HoltAtherton Special Collections. Used by permission. [Box. 4B.98.13: Brubeck Birthday Bash: (Tape 1)] Brubeck Collection, Holt-Atherton Special Collections, University of the Pacific Library. Copyright @ Dave Brubeck.
} 
be divided into two parts: the first spans over five choruses with a monophonic solo in the right hand and jazz comping in left hand. As Dave Brubeck did in his first recording, following the sax solo Darius gradually builds the culmination of his solo by changing the texture from chorus to chorus, all eight and a half choruses of this performance keeping the sixteen-measure structure. The last part of the piano improvisation is very percussive, in block chords with tremolo, glissando, and the $\mathrm{B} b$ 7/9 chord. Darius finalizes his solo with one and a half choruses in block chords in repetition, carrying the same polytonal sound of his father's original recording. Logically, his solo leads to the drum improvisation.

The four and a half choruses of Dan Brubeck's improvisation are filled with outstanding drills, polyrhythmic counter-lines, and syncopated embellishments. All the choruses of this solo keep the sixteen-measure structure ( $\mathrm{B} b$ eight and $\mathrm{A} b$ eight measures). In the twenty-four-measure recapitulation (final head), the restatement of the basic theme by the full orchestra, topped by the freely improvised sax line, leads to a full tutti in the last seven measures. In form, this realization is the closest to the original jazz trio version.

\begin{tabular}{|c|c|c|c|c|c|}
\hline \multicolumn{6}{|c|}{ Jazzanians - 1995 private recording with LSO } \\
\hline Intro & $\begin{array}{c}\text { Main Theme } \\
\text { (the Head) }\end{array}$ & Improvisation & Improvisation & Improvisation & $\begin{array}{c}\text { Main Theme } \\
\text { (the Head) }\end{array}$ \\
\hline $\begin{array}{l}\text { Strings/ } \\
\text { Orchestra }\end{array}$ & $\begin{array}{l}\text { Alto Sax with a } \\
\text { full orchestra }\end{array}$ & Sax Solo & Piano Solo & Drums Solo & $\begin{array}{l}\text { Alto Sax with a } \\
\text { full orchestra }\end{array}$ \\
\hline $\begin{array}{l}20 \mathrm{~mm} . \\
(4+16)\end{array}$ & $24 \mathrm{~mm}$. & $\begin{array}{l}48 \mathrm{~mm} . \\
(3 \times 16)\end{array}$ & $\begin{array}{l}136 \mathrm{~mm} . \\
(8.5 \times 16)\end{array}$ & $\begin{array}{l}72 \mathrm{~mm} . \\
(4.5 \times 16)\end{array}$ & $\begin{array}{l}25 \mathrm{~mm} . \\
(24+1)\end{array}$ \\
\hline \begin{tabular}{|l|} 
First 4th \\
measures- \\
ostinato motive \\
in strings; the 16 \\
measures-full \\
orchestra
\end{tabular} & & $\begin{array}{c}3 \text { Choruses } \\
\text { ( } 8+8 \text { measures } \\
\text { structure) } \\
\text { Bass vamp on } \\
\text { B b / A b }\end{array}$ & $\begin{array}{l}8.5 \text { Choruses } \\
\text { Bass - vamp on } \\
\text { B b / Ab }\end{array}$ & $\begin{array}{l}\text { 4.5 Choruses } \\
\text { Bass - vamp on } \\
\text { B b / Ab }\end{array}$ & $\begin{array}{c}\text { Final-last } \\
\text { measure }\end{array}$ \\
\hline $\mathrm{mm} \cdot 1-20$ & $\mathrm{~mm} \cdot 21-44$ & $\mathrm{~mm} .45-92$ & $\mathrm{~mm} .93-228$ & $\mathrm{~mm} \cdot 229-300$ & $\mathrm{~mm} \cdot 301-325$ \\
\hline $0: 33$ & $0: 39$ & $1: 16$ & $3: 23$ & $1: 42$ & $0: 37$ \\
\hline
\end{tabular}

Example 21. The main divisions of the "Jazzanians" performance with LSO from 1995.

At the same time, the use of a full symphony orchestra allowed the composer to explore a variety of timbres, colors, and tones that added brilliance to the original material, making it shine as a true showpiece. This performance 
represents the fullest and most grandiose realization of the "Jazzanians" tune, revealing an outstanding example of music that combines classical and jazz traditions.

\section{THE FOURTH REALIZATION, RECORDED IN 1997}

Brubeck continued to explore the possibilities offered by the "Jazzanians" theme in another transformation. His idea was to extend the Quintet Sonata and rearrange it for another famous ensemble, the "Brodsky Quartet," a British string quartet founded in 1972, which, in addition to performing classical music, collaborated with eminent jazz, rock and pop composers. ${ }^{30}$ On March 12, 1996, Iola, Brubeck's wife wrote to John Salmon: "We have been told that the Brodsky String Quartet intends to perform the Chromatic Fantasy piece at the opening of a music festival in London in late June." 31 A year later the above named group recorded the four-movement version of the sonata entitled Chromatic Fantasy for String Quartet. ${ }^{32}$

In the introduction to the recording, Erik Levi said: "All three composers [Brubeck, Stravinsky, and Weill] have crossed the boundaries (real and imaginary) between Classical and Jazz or vice versa ... Brubeck is American but his acclaim has been international and in recent years he has won plaudits in the Classical world at the ripe age of 77!"33 Both the Brodsky Quartet's recording (1997) and the 2003 solo piano edition by Warner Brothers Publications include a fugue, which was composed after the other three movements, around 1996. ${ }^{34}$ By composing this fugue for the Brodsky Quartet, Brubeck put together the entire cycle for the first time. The nature of the ensemble offered Brubeck the opportunity to pursue a classical quartet sound, returning to the initial idea found in the 1988 manuscript. The "Jazzanians" theme continues to be heard as part of the countersubject of the newly composed fugue and also as the central middle section of the last movement of the Quintet Sonata.

An analysis of the Chaconne movement, which corresponds to the Quintet Sonata, shows that Brubeck kept the entire structure of the quintet version. Let's highlight the differences between the versions rather than describing the

\footnotetext{
${ }^{30} \mathrm{http}: / /$ www.brodskyquartet.co.uk/aboutus/brodskygrouphistory.html

${ }^{31}$ From Iola Brubeck to John Salmon, March 12, 1996. [Private correspondence.]

${ }^{32}$ Stephen Crist, ed. "Bach Perspectives." Bach in America 5 (Urbana, IL: University of Illinois Press, 2003), 210.

${ }^{33}$ Brodsky Quartet, Silva Classics, SILKD 6014 (1997), liner notes.

${ }^{34}$ Dave Brubeck e-mail to John Salmon. [Private correspondence, undated; Salmon's guess is late 1995 or early 1996.]
} 
similarities. The Brodsky Quartet recording is 13 minutes and 24 seconds long-30 seconds longer than An Die Musik's. Omitting the piano part, Brubeck rearranged the orchestration, developing a different distribution of the melodic lines, harmony, and the motoric movement of the ostinato motive. He manages to redistribute the voices in such a manner that the material found in the piano part of the An Die Musik version is naturally absorbed by the four string parts without noticeable losses. Only a "head to head" comparison of the recordings reveals a fuller, warmer sound of the quintet version and the more crisp sonority of the quartet display. In the new version the cello and viola parts undergo significant changes in terms of responsibilities. The cello part, for example, takes over the syncopated lines of the piano left hand, which makes the part more challenging. The overall effect of the new orchestration is a clearer chamber sound, allowed by the transparent, four-voice string score. Not surprisingly, on the chamber sonority background, the quartet achieves its jazziest sound in the 5/4 time signature. Example 22, describing Variation 10, highlights one of the fragments where cello and viola carry the offbeat accompaniment, emphasizing the irregular meter. To demonstrate the complexity of this fragment, Example 22 points out the appearance of the Petrushka harmonies interwoven into the syncopated cello part of the "Take Five" episode $(\curvearrowright\lrcorner \Omega\lrcorner \downarrow\rfloor)$. 


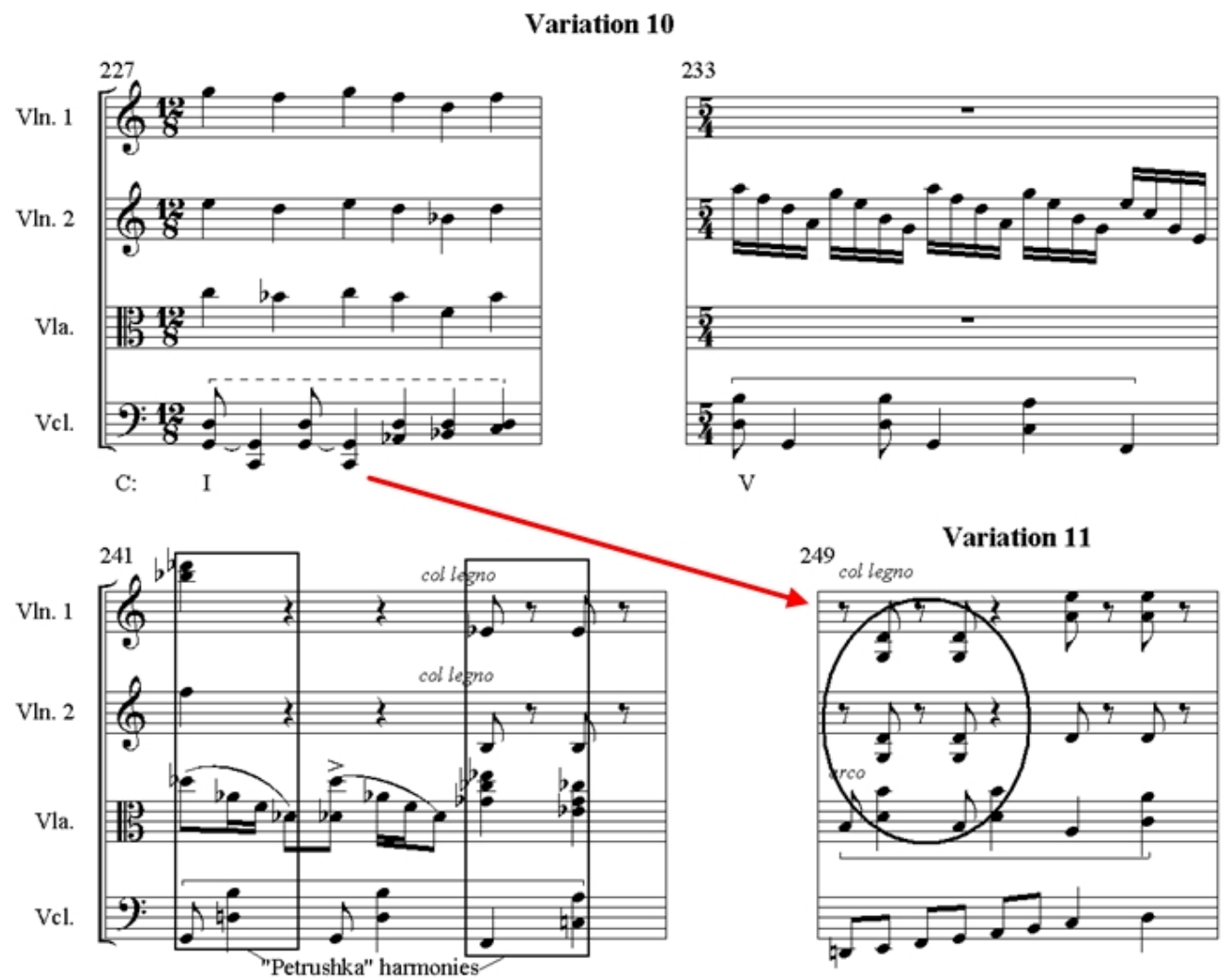

Example 22. Variation 10, mm. 227-248, ostinato motive and "Take Five" rhythm. ${ }^{35}$

In the introduction, the melodic theme is given to the first and second violins, while the viola (carrying the ostinato motive) and the cello (playing the downbeats of the ostinato motive) are responsible for keeping the motoric feel. Moreover, the original legato of the ostinato motive was replaced by spiccato, lending the motive a scherzando character. In the central section (mm. 85-100), the "Jazzanians" theme is utilized to create harmonic planing by being placed in parallel voices. Starting in m.101, unlike in the An Die Musik version, where the first violin led the top voice, the string quartet orchestration assigns the upper voice to the second violin. In the same middle section Brubeck masterfully uses the pizzicato possibilities of the string quartet to create a guitar-like accompaniment for the top voices. To emphasize the swing, Brubeck places the accompanying voices of the violins in long and short off

35 [Chromatic Fantasy for String Quartet, Chaconne] Brubeck Collection, Holt-Atherton Special Collections, University of the Pacific Library. (C) Dave Brubeck 
beats of 5/4. Moreover, he creates hemiolas, and-to continue the development-alternates between $6 / 4$ and 3/4 time signatures, and employs cross rhythms on a large scale by counterpointing the motive taken from the 5/4 rhythm with the accompaniment.

The most significant difference between the scores occurs in the meter. Brubeck rearranges the score in 12/8 meter, instead of 4/4 in triplets and sextuplets, permitting a smoother reading for the musicians and a calmer feel of the motoric ostinato drive.

Last but not least, the insertion of the Fugue movement in the Chromatic Fantasy for String Quartet allowed for one more manifestation of the "Jazzanians" motive, where it appears as part of the countersubject. Thus, in this version of the Chromatic Fantasy, the "Jazzanians" motive appears in all four movements, performing a unifying function, which raises its importance within the cycle to a new level.

\section{THE FIFTH REALIZATION, RECORDED IN 2004}

The final recorded realization of the "Jazzanians" is represented by the solo piano version of the Chromatic Fantasy Sonata performed by John Salmon (CD recording release-2/1/2004). The development of this realization began as far back as 1992 and benefited at times from Brubeck's collaboration with John Salmon.

Salmon had been Brubeck's editor, performed his music, and written extensively about his work. ${ }^{36} \mathrm{He}$ is an editor of the piano book Seriously Brubeck, which includes the Chromatic Fantasy Sonata, published by Warner Bros. in 2003. ${ }^{37}$ His connection with Brubeck was strong, developing through many years. About him Brubeck said: "My association with pianist John Salmon began over thirty years ago. It came in the form of a letter from a young man, who played both jazz and classical piano, seeking advice about pursuing a professional career in music." 38

In a telephone conversation in 2010, Salmon offered details about the "Jazzanians" and the sonata, and shared his private correspondence related to this project. The correspondence makes clear that from a very early stage Brubeck had the idea to realize the composition for solo piano as well as for quintet. In 1992, he wrote to Salmon: “The 'Jazzanians' piece should not be played until the chamber group An Die Musik premieres it, as they commissioned it. But after the first performance, you should be able to do it, if

${ }^{36}$ http://www.johnsalmon.com/John_Salmon/Articles.html

${ }^{37}$ Lew and Salmon, 7.

${ }^{38}$ Brubeck, Chromatic Fantasy Sonata / Rising Sun, 1. [Liner notes] 
you like it. There are three other movements in this piece that I may be able to adapt for solo piano, as I have done with this third movement." 39

In 1994, Brubeck transcribed for piano and published the three movements of the quintet version of the sonata. Two years later, he composed the fugue movement for string quartet, which was immediately transcribed for piano by John Salmon. From Brubeck private correspondence with John Salmon in early 1996: "This is the fugue with the 12 -tone theme from the $1^{\text {st }}$ mvt. of Chromatic Fantasy and the different 12 -tone theme from the $2^{\text {nd }}$ mvt. These themes become the subject and the countersubject of the fugue. They also made it very hard to write and you may not think it worthwhile to make a piano piece from it. You are free to change the octaves if the spread is too much, or you can even leave out a voice if it is too difficult to keep them all playing." ${ }^{40}$ With the inclusion of Salmon's transcription of the fugue, the piano sonata found its completion. In 2001, writing to Dave Olsen, an editor at Warner Bros., Brubeck said: "Dear Dave, When I was talking to you today I forgot one important thing. I have had on my desk for a week to call you about inserting the Fugue into the next printing of Chromatic Fantasy for solo piano... To me, the piece is not complete without the Fugue." 41

Not surprisingly, in this fifth realization the "Jazzanians" theme continues to bear the main role of the cycle as a part of the countersubject of the new transcribed fugue, as well as holding the main role in the middle section of the Chaconne movement. Analysis of Salmon's performance in 2004 demonstrates that he followed Brubeck's example of rearranging the voices from the previous versions by adapting the range of the fugue's voices for solo piano. When describing the style of his interpretation of the piano transcription in his book, Seriously Brubeck, Salmon states that: "the Chaconne is based on a jazz riff," thus emphasizing the stylistic impact of the "Jazzanians" motive on this work. However, he kept a strong "classical" sound in the "Jazzanians" section, supporting the idea of a fusion of jazz and classical traditions. ${ }^{42}$ The Chaconne represents Brubeck's final reformulation of the sonata's main ideas and contrasts, where he reworks the main thematic material and develops it

\footnotetext{
${ }^{39}$ From Dave Brubeck to John Salmon, July 30, 1992. [Private correspondence, Brubeck was writing about the "Jazzanians" and Chaconne.]

${ }^{40}$ From Dave Brubeck to John Salmon. [Private correspondence, undated; Solmon's guess is late 1995 or early 1996, Brubeck was writing about the Fugue and the themes.]

${ }^{40}$ Letter from Dave Brubeck to Dave Olsen at Warner Bros., Nov. 27, 2001. [Private correspondence]

${ }^{41}$ Ibid

${ }^{42}$ Gail Lew and John Salmon, 4.
} 
according to his jazz background. The synthesis of Baroque traditions with the rhythmic and harmonic language borrowed from his modernist, jazz-inspired works gives the movement a unique place in this genre.

Example 23 provides a comprehensive demonstration of the overall structure of the four-movement cycle, where classical and jazz traditions commingle to create a distinct style.

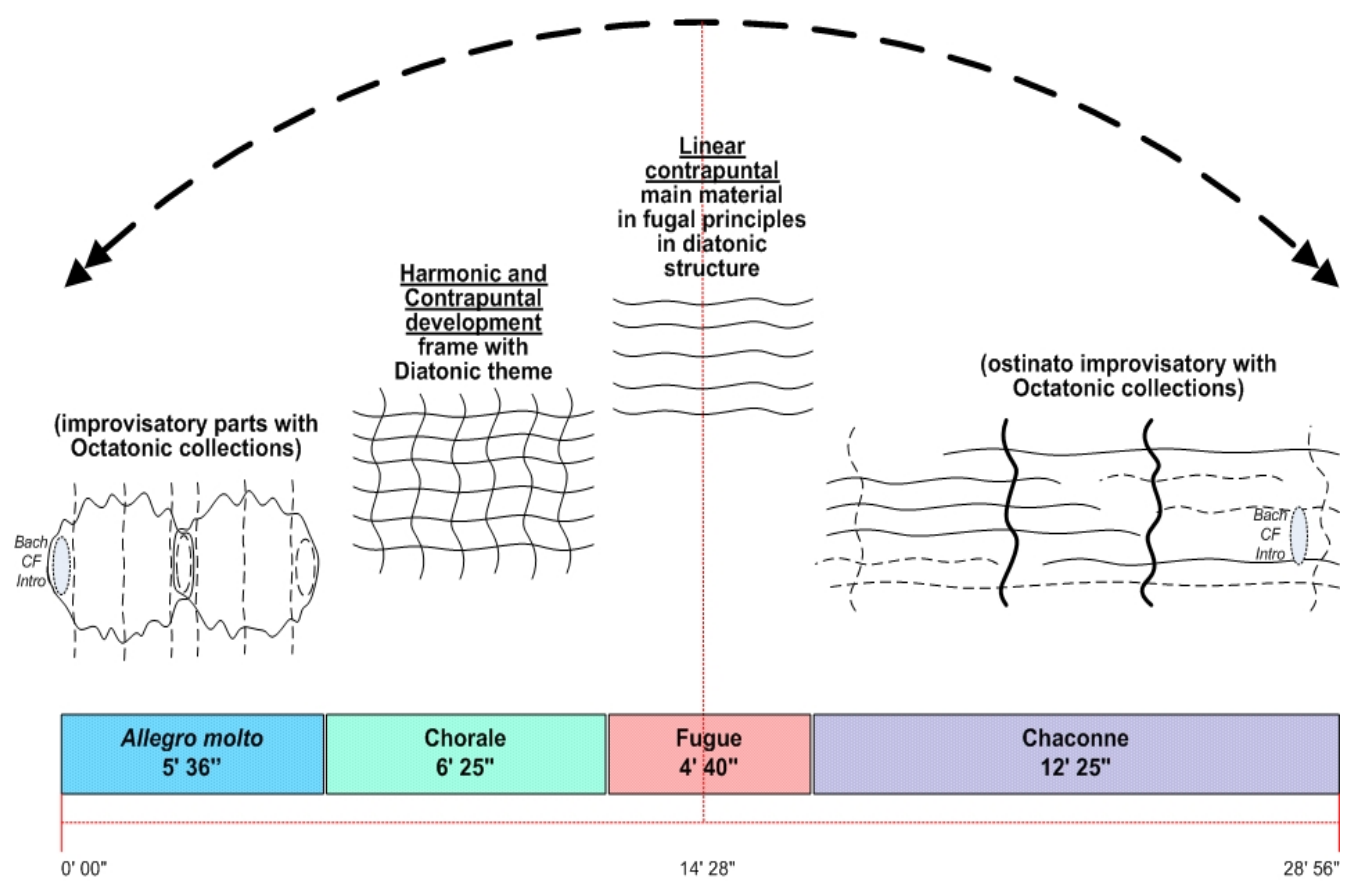

Example 23. Proportional diagram of John Salmon's performance on Chromatic Fantasy Sonata.

\section{CONCLUSION}

The following table, Example 24, shows the structural evolution of the "Jazzanians" tune from the original motive to the various forms it achieved in the later realizations. 


\begin{tabular}{|c|c|c|c|}
\hline \multicolumn{4}{|c|}{ Jazzanians - motive \& theme } \\
\hline Date & Versions \& publications & Form structure & $\begin{array}{l}\text { Length (in } \\
\text { minutes) }\end{array}$ \\
\hline 1987 & "Jazzanians" Manuscript & $\begin{array}{c}16 \text { measures } \\
\mathrm{Bb}\end{array}$ & - \\
\hline 1992 & Trio Brubeck recording & $\begin{array}{c}\text { 24-measure theme (with repeat), and } \\
\text { seven and half sixteen-measure } \\
\text { improvisations } \\
{[\mathrm{B} b / \mathrm{A}]}\end{array}$ & $\begin{array}{l}7: 57 \text { min. } \\
\text { ( Trio Brubeck } \\
\text { recording) }\end{array}$ \\
\hline 1993 & $\begin{array}{l}\text { The first publication of } \\
\text { "Jazzanians" }\end{array}$ & $\begin{array}{c}3 / 4 \text { "Fast Waltz" version, added a new } \\
12 \text {-tone theme and extended by means } \\
\text { of new material }\end{array}$ & (Never recorded) \\
\hline 1994 & $\begin{array}{l}\text { Part of "Quintet Sonata" } \\
\text { (middle section) }\end{array}$ & $\begin{array}{c}4 / 4 \text { "Jazzanians" version was } \\
\text { transferred to the section B ; added } 2 \\
\text { variations }\end{array}$ & $\begin{array}{l}12: 54 \text { min. } \\
\text { (An Die Musik's } \\
\text { recording) }\end{array}$ \\
\hline 1995 & $\begin{array}{l}\text { Orchestral version of } \\
\text { "Jazzanians" }\end{array}$ & $\begin{array}{c}\text { 24-measure theme (with repeat), and } \\
\text { a long improvisational section as in } \\
\text { the trio version }\end{array}$ & \begin{tabular}{|} 
8:17 min. \\
(Brubeck's \\
private recording \\
with $L S O$ )
\end{tabular} \\
\hline- & $\begin{array}{l}\text { Orchestral version of Chaconne } \\
\text { movement with title III Fantasy } \\
\text { Chromatique }\end{array}$ & $\begin{array}{c}\text { The same structure as } \\
\text { "Quintet Sonata" }\end{array}$ & $\begin{array}{c}\text { (Never performed } \\
\text { or recorded) }\end{array}$ \\
\hline 1997 & $\begin{array}{l}\text { Chaconne movement of } \\
\text { Chromatic Fantasy Sonata }\end{array}$ & $\begin{array}{c}\text { Entire movement and “Jazzanians" } \\
\text { was written in } 12 / 8 \text {, the texture and } \\
\text { structure are the same as quintet } \\
\text { version }\end{array}$ & $\begin{array}{c}13: 24 \text { min. } \\
\text { ("Brodsky Quartet } \\
\text { recording) }\end{array}$ \\
\hline 2003 & \begin{tabular}{|} 
The final published version of \\
the Chromatic Fantasy Sonata; \\
solo piano recording by John \\
Salmon in (CD release-2/1/2004)
\end{tabular} & $\begin{array}{l}\text { The same structure as } \\
\text { "Quintet Sonata" }\end{array}$ & $\begin{array}{l}\text { 12:15 min. } \\
\text { ( John Salmon's } \\
\text { recording) }\end{array}$ \\
\hline
\end{tabular}

Example 24. The development of the structure of "Jazzanians," 1987-2004.

Brubeck's numerous realizations of the basic "Jazzanians" material allowed him to discover rich combinations in a complex and challenging project. This "improvisational" process extended from the end of the 1987, when he was inspired by the "Jazzanians" musicians from Africa, to the last recording of the piano transcription of the Chromatic Fantasy Sonata in 2004. The composition represents the transference of Brubeck's jazz-based improvisational thinking to a composed piece of concert-hall music.

Brubeck's experience in writing "academic" music, using unique polyrhythmic and complex harmonic constructions, can be observed in his "classical" second, fourth and fifth realizations, while some of the material can be related to earlier compositional efforts. With the five different orchestrations Brubeck proved that he is not only a creative composer, but also a fluent orchestrator. Besides rearranging and orchestrating the tune for 
different ensembles, he himself served as its interpreter in concerts. His initial idea of realizing a jazz tune yielded to a "classical" composition that was deeply indebted to his improvisational principles, while tracing the variations that emerged from the "Jazzanians" tune allows for a glimpse into the composer's original thinking.

"Jazzanians" represents an eclectic compositional intellect exploring a wide range of thematic, harmonic, and rhythmic approaches including the opposition of diatonic and chromatic harmonic thinking, and the derivation of a series of themes from a small number of related motivic cells. In the third realization of "Jazzanians," jazz and classical techniques meld into one harmonious entity. Confirmation comes from Brubeck's own statement: "The question I am repeatedly asked is 'What is the difference between your composed pieces and your piano improvisation?' My approach to writing for the piano is basically the same as my approach to improvisation, the difference being the gift of time and opportunity to edit, rewrite and refine what is written." 43

Tracing the variations that Brubeck created from the "Jazzanians" tune provides a glimpse into the mind of this original composer. Over a period of 17 years, he developed many versions representing the crossover of jazz and classical styles. With the five different orchestrations Brubeck proved that he is not only a creative composer, but also a fluent orchestrator. He collaborated with many different groups and artists, influencing generations of musicians.

What was Brubeck searching for? He leaves us a legacy of wonderful music, including the many variations of the "Jazzanians" tune. Each realization appeared to be more definitive then the one before. However, examining all five realizations, I have come to believe that each one underscores Brubeck's genius.

\section{WORKS CITED}

Brubeck, Dave. Liner notes to Jazz Sonatas. Angel Records. CDC 5-55061-22. . Liner notes to Brodsky Quartet. Silva Classics. SILKD 6014. . Liner notes to Brubeck: Chromatic Fantasy Sonata/Rising Sun. Naxos. B000QQP9KY.

Brubeck, Darius. "A South African Story about Jazz Education: Beginnings, Development and Drinks at 5." Paper presented at the Rhythm Changes: Jazz and National Identities Conference, Amsterdam, 2011.

\footnotetext{
${ }^{43}$ Brubeck, Chromatic Fantasy Sonata / Rising Sun, 1.
} 
Crist, Stephen, ed. "Bach Perspectives." Bach in America, Vol.5, Urbana, IL: University of Illinois Press, (January 2003): 179-215.

Cook, Nicholas and Mark Everest, eds. Rethinking Music. New York: Oxford University Press, 1999.

Cvetkov, Vasil Atanasov. "Chromatic Fantasy Sonata by Dave Brubeck." PhD diss., Louisiana State University, 2010.

Emmerich, Constance. The program notes for the premiere in Kennedy Center's Terrace Theatre, Washington, DC, March 16, 1994. . Liner notes to Merkin Concert Hall program. 1994.

Enstice, Wayne and Paul Rubin. Jazz Spoken Here: Conversation with TwentyTwo Musicians. Baton Rouge, LA: Louisiana State University Press, 1992.

Gridley, Mark. Jazz Styles: History and Analysis. Upper Saddle River, NJ: Prentice Hall, 2003.

Hall, Fred M. It's About Time: The Dave Brubeck Story. Fayetteville, AK: University of Arkansas Press, 1996.

Hodson, Robert. Interaction, Improvisation, and Interplay in Jazz. New York: Routledge Taylor \& Francis Group, 2007.

Young III, Harmon Griffith. "The Sacred Choral Music of Dave Brubeck: A Historical, Analytical, and Critical Examination." PhD diss., University of Florida, 1995.

Larson, Steve. "Composition versus Improvisation?" Journal of Music Theory, 49.2 (2005): 241-75.

Lees, Gene. Cats of Any Colors. New York: Oxford University Press, 1994.

Lyons, Leonard S. The Great Jazz Pianists: Speaking of Their Lives and Music. New York: William Morrow and Company, Inc., 1983.

Martin, Henry. "Jazz Harmony: A Syntactic Background." Annual Review of Jazz Studies 4: 9-30.

McFarland, Mark. "Dave Brubeck and Polytonal Jazz." Jazz Perspectives Vol. 3, No. 2 (2009): online.

McCreless, Patrick. "Syntagmatics and Paradigmatics: Some Implications for the Analysis of Chromaticism in Tonal Music." Music Theory Spectrum, Vol. 13, No. 2 (Autumn, 1991): 147-178.

McPartland, Marian. Liner notes to Marian McPartland's Piano Jazz with Guest Dave Brubeck. Jazz Alliance.

Ratliff, Ben. "For Brubeckians, Classical Brubeck." New York Times, June 23, 1999, E.5.

Salmon, John C. to Vasil Cvetkov, [Private correspondence with Dave and Iola Brubeck], electronic mail, October 31, 2008.

Salmon, John C. "Dave Brubeck: No Time To Take Five." Piano Today, Vol. 28, No. 3 (Summer 2008): 2-4. 
. "What Brubeck got from Milhaud."

http://www.uncg.edu/ jcsalmon/articles.html (accessed October 1, 2009).

Shapiro, Nat and Nat Hentoff, eds. Hear Me Talkin' to Ya: The Story of Jazz as

Told by the Men Who Made It. New York: Dover Publication, Inc., 1966.

Smith, Ken. "Reviews: CDs." Strad 108(1292) (Dec. 1997): 1392. Review of

Brubeck's composition Chromatic Fantasy as performed by the Brodsky Quartet."

Straus, Joseph N. Remaking the Past. Cambridge MA: Harvard University Press, 1990.

Storb, Ilse and Klaus-G. Fischer. Dave Brubeck. Improvisations and

Compositions. The Idea of Cultural Exchange. New York, N.Y.: Peter Lang Publishing, Inc., 1994.

Stuessy, Clarence J. "The Confluence of Jazz and Classical Music from 1950 to 1970.” PhD diss., University of Rochester, 1977.

University of the Pacific. About The Brubeck Institute http://www.pacific.edu/Community/Centers-Clinics-andInstitutes/Brubeck-Institute/About-the-Institute.html (accessed September 18, 2013).

Van den Toorn, Pieter C. The Music of Igor Stravinsky. Yale University Press, 1983.

Online Sources

$3^{\text {rd }}$ EarMusic.

http://www.3rdearmusic.com/reissue/jazzanians.html

(accessed August 18, 2013).

http://www.brodskyquartet.co.uk/aboutus/brodskygrouphistory.html

http://www.johnsalmon.com/John_Salmon/Articles.html

(accessed August 18, 2013).

Musical Scores

Brubeck, Dave. "Chromatic fantasy" sonata: commissioned and first performed by An Die Musik. Derry Music Co. Miami, Fl., 1994. (Not in print publication, includes movements Chorale and Chaconne).

Brubeck, Dave. Chromatic Fantasy. Derry Music Co. Miami, Fl., 1996. (Quartet score, unpublished, includes entire four-movement sonata).

Brubeck, Dave. Chromatic Fantasy. (Orchestral score, unpublished, includes fourth movement-Chaconne, around 1995). 
Roed, Tom, ed. At The Piano with Dave Brubeck. Intermediate Solos Arranged by Dave Brubeck. Miami, FL: CPP/Blewin, Inc, 1993.

Lew, Gail and John Salmon, ed. Seriously Brubeck. Original Music by Dave Brubeck. Warner Bros. Publication, 2003.

\section{Sound Recordings}

Brubeck, Dave. 1993. Trio Brubeck. Music Masters. 65102-2.

Brubeck, Dave. 1994. Jazz Sonatas. Angel Records. CDC 5-55061-2-2.

Brubeck, Dave. 1997. Brodsky Quartet. Silva Classics. SILKD 6014.

Dave Brubeck 2004. Brubeck: Chromatic Fantasy Sonata/Rising Sun. Naxos. B000QQP9KY.

Brubeck, Dave. [Two private recordings. Brubeck Collection in the HoltAtherton Special Collections at the University of the Pacific, California].

\section{ABOUT THE CONTRIBUTOR}

VAsil CVetKov is a Lecturer in Music at Southeastern Louisiana University. $\mathrm{He}$ has also taught at Louisiana State University in Baton Rouge, where he received his Ph.D. in Music Theory and Jazz Study. Cvetkov has delivered papers on Brubeck at national and international conferences. His academic research examines the interplay of classical and jazz works by contemporary composers.

The Journal of Jazz Studies (JJS) is published by the Institute of Jazz Studies at the Newark campus of Rutgers, The State University of New Jersey. JJS is hosted online by the Rutgers University Libraries at http://jjs.libraries.rutgers.edu 